\title{
Effects of Water Wave Motions on Spectral Characteristics of Wind Fluctuations in the Marine Atmospheric Surface Layer
}

\author{
By Atsushi Takeda \\ Institute of Coastal Oceanology, National Research Center for Disaster Prevention, \\ Science and Technology Agency, Hiratsuka 254, Japan \\ (Manuscript received 28 February 1981, in revised form 6 June 1981)
}

\begin{abstract}
Spectral characteristics of wind velocity fluctuations in the marine atmospheric surface layer were investigated using data collected in field observations mostly at a tower in the sea, with paying special attention to possible effects due to wave motions of the water surface.

The data of wind fluctuations and waves measured simultaneously in the cases when both winds and waves traveled toward almost the same directions were selected and analyzed. Two-dimensional wind fields in the plane parallel to the mean horizontal wind direction ( $u$-component) and to the vertical direction ( $w$-component) were discussed.

The wind velocity spectra of $u$ - and $w$-components in the lower frequency region, observed over sea, deviate upward from those model spectra proposed by Kaimal et al. (1972) and by Busch (1973) on the basis of Monin-Obukhov's similarity theory.

From the coherence function analyses, it was found that the wind velocity fluctuations over sea contain a fairly good amount of 'wave coherent perturbations' in addition to the regular turbulences in the atmospheric surface layer. A spectrum excluding the spectral contribution of the wave coherent perturbations shows almost to agree with the model spectrum. The perturbation seems to give little contribution to a cospectrum between $u$ and $w$, and may, therefore, not yield any significant amount of vertical momentum flux.

The results of the frequency response function analyses suggest that the pattern of motion of the perturbation may be an ellipse with a horizontal axis a little longer than a vertical one. The results also suggest that the perturbation may be induced effectively by the wave components whose phase speeds are faster than the measured wind speed, and that an attenuation of the perturbation amplitude with height is small in the observed range of height $(50-400 \mathrm{~cm}$ above the mean sea level).

From the above mentioned experimental results, the wave coherent perturbations were recognized as an origin to increase the spectral densities in the lower frequency region. The wave effects on spectral characteristics of winds in the marine atmospheric surface layer may have been first described in this study on the basis of the similarity theory.
\end{abstract}

\section{Introduction}

Our understanding of characteristics of wind velocity fluctuations in the marine atmospheric surface layer is still insufficient to interpret physical processes of the air-sea interaction.

In general, the spectra and cospectra of turbulences in an atmospheric surface layer are considered to have universal forms described by parameters such as the friction velocity and the stability parameter, according to Monin-Obukhov similarity theory (Monin and Obukhov, 1954). The large amounts of data collected 'over land' by various investigators to date show clear indication that the spectra and cospectra obey the theory over a broad frequency range of turbulent fluctuations (Lumley and Panofsky, 1964).

The prediction, however, has not been verified for the wind velocity fluctuations in an atmospheric surface layer 'over sea'. Since Busch and Panofsky (1968) suggested that the spectral density of wind velocity components over sea, other things being equal, are larger than those over land in the lower frequency range, the problem has been still disputable. Some observational results support their view (e.g. Davidson, 
1974), while others reveal validity of the similarity relation even over sea (e.g. Schmitt et al. 1978).

The major difference of physical properties between sea and land is that the former has the free boundary surface which can easily deform and undulate against wind stresses acting on it. The undulations must change the roughness of water surface. If the effects of surface undulations on the spectra are entirely due to the difference in roughness, it can be explained completely in context of the similarity theory and no deviation will originate in the spectra.

There are some evidences suggesting that winds over water surfaces undergo a dynamical effect from underlying wave motions. Miles (1957, 1967) predicted in his theory on wave generation by wind that there might be expected a presence of wave-like perturbations in the winds around a level where the mean wind speed is equal to the phase speed of an underlying water wave component. The process by which the perturbations are induced and amplified is referred to a critical layer instability and has been considered one of the most possible way to transfer momentum from winds to waves. In facts, results of experimental studies in laboratories by various investigators showed the presence of wind perturbations of this category (e.g. Lai and Shemdin, 1972, Kato and Sano, 1972). Kondo et al. (1974) also reported wave induced perturbations in the longitudinal wind component which were detected from field observation data over swells.

From another point of view, Volkov (1969) suggested that a predominant swell component has an effect on the standard deviations of wind fluctuations measured over waves.

According to these facts, it seems to be reasonable to infer that waves give another dynamical effect besides the roughness on winds blow over them, or more strictly, waves particularly of lower frequency components induce perturbations in winds which may differ from ordinary turbulences generated by the shear friction.

There has been very few report with any discussion on spectral characteristics of the marine surface layer, taking account of the perturbations. Only Benilov et al. (1974) showed that estimated spectral densities of wave coherent perturbations in winds could eliminate irregularities in individual spectra of wind fluctuations over waves, but they did not notice about the general discrepancy between spectra of over-land and of over-sea in context of the similarity relation.

We must go a step further and apply the conception of wave coherent perturbations to interpretation of the descrepancy in term of the similarity law. Taking this approach, the present study aims to describe possible wave effects on the characteristics of spectra and cospectra of wind velocity fluctuations based on the results of field experiments. The investigation is carried out in accordance with the following processes.

1) A large number of records of simultaneously measured three-dimensional wind velocity fluctuations and waves (water level fluctuations) are collected through a series of field observations.

2) Spectral analyses of the collected data are carried out. Peaks in a wave spectrum are marked. Normalized spectra and cospectra of each wind velocity component are compared with the over-land results by other investigators, to check validity of the similarity theory in a marine surface layer.

3) Coherence functions between waves and wind fluctuations are calculated from the results of spectral analyses to examine presence of wave coherent perturbations. If the coherences are not zero, then spectral magnitudes of the wave coherent perturbations are estimated as a coherent portion of each wind spectrum assuming that the perturbations are outputs of a linear system excited by waves.

4) Frequency response functions of the assumed linear system are determined to detect any dependence of the function on frequencies, wind speeds and heights, and thereby to graspe characteristics of the perturbations.

5) Finally possible dynamical wave effects are discussed based on the total results of the processes mentioned above.

\section{Description of the data}

\subsection{Observation site}

Most data were obtained at the Hiratsuka Marine Observation Tower standing in the sea about $1 \mathrm{~km}$ south off Shonan Beach, Kanagawa, Japan, which extends almost straight along the east-west direction and faces to the Pacific Ocean. The water depth at the site is about $20 \mathrm{~m}$ and the bottom is a flat sand surface with a gentle slope toward the shore. Details of the tower were described by Kondo et al. (1972). The tower has preferable observational conditions like open oceans against the south-easterly to southwesterly winds. In these cases, the fetches are more than $50 \mathrm{~km}$ and swells from the open ocean propagate almost parallel to wind waves. Distor- 
tions and breakings of waves due to the bottom effect were negligible at the site under a light wind and moderate swell condition. When wind speed exceeds $7 \mathrm{~m} / \mathrm{s}$, an operation of the precise observation becomes considerably difficult because of spray from white-capped waves.

In addition to these data, a certain number of data from the over-lake observations on the Lake Biwa, Shiga, and the Lake Kasumiga-ura, Ibaraki, were used for reference of the cases with short fetches $(4-10 \mathrm{~km})$ and without predominant swells. In all these cases winds blew from lake to land.

\subsection{Instrumentation}

In each observation, the three-dimensional wind velocity fluctuations at one or two levels up $5.1 \mathrm{~m}$ above the mean water surface and the fluctuations of water level just under the anemometry points were measured simultaneously, together with the mean temperatures of air and surface water.

Wind velocity fluctuations were measured with a three-dimensional ultrasonic anemometer (Kaijo Denki model PA-321, but in the observation in 1967 its prototype model was used). Every specification item of the anemometer but the dimensions of its probe is very similar to that of model PA-311 of the same manufacturer, on details of which Mitsuta (1968) reported. A probe consists of three vector component sensors; one vertical and two horizontal ones. Two horizontal components cross at a wide angle of $120^{\circ}$ each other so that even the most fluctuating wind can be encountered in this angle without any blocking by the frame supporting the sensors. The measuring span of each sensor is about $10 \mathrm{~cm}$ and the three sensors are arranged within a smaller space of $10 \mathrm{~cm}$ cube than of the other models. The output signals from the two horizontal sensors were transformed into two orthogonal vector components at a stage of data processing.

Water level fluctuations were recorded with an electric capacitance type wave gauge (Denshi Kogyo model VM-105). A probe of the gauge consists of a Tefron coated copper wire $1.6 \mathrm{~mm}$ in diameter stretched vertically by a stiff supporting frame. The Tefron coat, the copper wire and the surrounding water operate as a dielectric body and two electric plates of a condenser, respectively. The gauge has excellent characteristics of the linearity and the frequency response of the output. The detailes were described by Inada and Watabe (1969).

Directions of wave propagation were ob- served with eyes and photographs from the top of the tower about $20 \mathrm{~m}$ high above the mean sea level. Wind waves might be regarded as propagating almost parallel to overlying winds.

Mean temperatures at $10 \mathrm{~m}$ height and of the water surface were read from the thermister thermometers every two minutes during the period of each observation.

Probes were installed on a vertical steel pole $50 \mathrm{~mm}$ in diameter with arm adaptors that their centers aligned on a single vertical line. In cases of the Hiratsuka Tower observation, in order to avoid the disturbances around the tower structures, the equipped pole was fixed at the outer end of a $4 \mathrm{~m}$ boom horizontally swung out toward south (nearly upwind directions) from a windward edge of the lower deck of the tower about $2 \mathrm{~m}$ high above the mean water level. In the over-lake observations, the pole was set up directly on the water bottom and fixed by three wire stays.

The heights of anemometer probes were varied in a range between $0.4 \mathrm{~m}$ and $5.1 \mathrm{~m}$ high above the mean water levels according to observations.

The orientation of an anemometer probe was checked so carefully with a built-in level that the vertical axis was exactly on a vertical line.

Each instrument was calibrated in a laboratory before and after every field operation. Adjustments of zero points of the anemometer outputs were done for every observation by sheltering the probe in a specially designed calibration chamber.

\subsection{Data processing}

All the output signals from anemometers and a wave gauge were of analog voltage. They were recorded simultaneously on an 8-track data recorder (Precision Instrument model PI-6208). Reference DC signals for calibration corresponding to zero and full scales of each output were also recorded on the same tape just before and after each data record.

The signals on magnetic tapes were monitored by an 8 channel chart recorder for checking their qualities. Erroneous parts in each record such that apparently contaminated by unremovable noises were rejected and only preferable parts were selected for analyses.

In conjunction with analog low-pass filtering, signals of the selected parts were sampled at a rate 5 points per second per channel almost in parallel for every channel by a high speed scanner, and digitized by an A-D converter into digital 
signals of 12 bits a point. Each filter used for each channel has a cut-off at $2.0 \mathrm{~Hz}$ and an identical characteristic curve of $-3 \mathrm{db} /$ octave. A time lag between each channel in one sampling was $1 \mathrm{~ms}$ at the maximum which might be negligible comparing with the sampling time interval of 0.2 seconds. The time series data of digital signals were divided into consecutive blocks of an equal length. Here each block is referred to one record. Each record was 410 seconds long and had 2048 points for each channel.

Reference DC signals for each record were also digitized and were reduced into zero bias values and gain factors. Then digital data signals were corrected by subtracting the zero-bias values and by multipling the gain factors.

The desirable coordinate system for interpreting wind velocity fluctuations is one with an axis parallel to the mean horizontal wind ( $x$-axis), an axis traverse in the horizontal ( $y$-axis) and an axis parallel to the vertical ( $z$-axis). These define, respectively, the three orthogonal vector components of wind velocity, $u, v$ and $w$ or longitudinal, lateral and vertical component. Such components were obtained from three wind components measured on the coordinate system attached on an anemometer probe, with two $120^{\circ}$ crossing horizontal axes and in an arbitrary orientation against a mean wind, through a twostep transformation of coordinate systems.

The obtained three orthogonal components, $u$, $v$ and $w$ have relations;

$$
\bar{u}=U, \quad \bar{v}=0, \text { and } \bar{w}=0 .
$$

where (and hereafter) the bar means an average over the period of a record (410 seconds), and $U$ is a mean horizontal wind velocity. Calculations of the transformation were practiced for simultaneously sampled data points of the three wind velocity components.

In general, an inclination of an anemometer probe originates serious errors due to interferences between each wind velocity component. Assume a tilt by an angle of $\delta$ in the $X-Z$ plane, then the apparent $u+U$ and $w$ are given as $(U+u) \cos \delta+w \sin \delta$ and $w \cos \delta-(U+u) \sin \delta$, respectively. Provided $\delta \ll 1$ and $w \ll U$, the former may be approximated to $U+u$, while the latter may be reduced to $w+(U+u) \delta$. This apparent $w$ would make much trouble for determination of the $u-w$ covariance and $u-w$ cospectrum. Pond et al. (1971) remarked that in order to get reasonably accurate values for the covariance $u w$, the maximum allowable inclination should be within 1 or $2^{\circ}$ of a correct coordinate system. In our observations, the inclination could be effectively within $\pm 0.5^{\circ}$ so far as installation of the probe is concerned. To make sure of it, examinations were done by the following way: $U$ and mean values of $w$-component i.e. $\bar{w}$ for each record in the same series of observation were plotted on a correlogram against each other. If $w$ was contaminated by $(U+u) \sin \delta$, an apparent $\bar{w}$ should depend on $U$. In most cases, however, the apparent $\bar{w}$ was essentially small, and any significant correlation was not found between $U$ and $\bar{w}$. An existing $\bar{w}$ is considered to be a bias due to a drift of a zero-point of the electronics and was suppressed into zero when the data were processed.

\subsection{Calculations of basic parameters}

The basic parameters which may represent statistical and observational features of every time series record were calculated. They are the mean (horizontal) wind velocity, $U$, the mean anemometer height, $z_{a}$, the variances and covariances of wind fluctuations and waves $\overline{u^{2}}$, $\overline{v^{2}}, \overline{w^{2}}, \overline{\zeta^{2}}, \overline{u v}, \overline{u w}, \overline{v w}, \overline{u \zeta}, \overline{v \zeta}, \overline{w \zeta}$, where $\zeta$ denotes the surface elevation, a friction velocity $u_{*}$ a stability parameter $z / L$ and phase velocities $c_{i}(i=1,2, \ldots)$ of peaking frequency components in the wave spectrum. A friction velocity $u_{*}$ was derived from a covariance $\overline{u w}$ as $u_{*}{ }^{2}=\overline{u w}$. The Monin-Obukhov length $L$ was determined by

$$
L=-\frac{c_{p} \rho T_{a 10} u_{*}{ }^{3}}{k g H}
$$

where $c_{p}$ is the specific heat at constant pressure, $\rho$ is the density of air, $T_{a 10}$ is the mean air temperature at $10 \mathrm{~m}$ height in Kelvin scale, $k$ is von Karman constant (taken to be 0.42), $g$ is the gravitational acceleration and $H$ is the heat flux which was approximately estimated by the bulk relation

$$
H=c_{p} \rho C_{H 10} U_{10}\left(T_{a 10}-T_{s}\right)
$$

where $C_{H 10}$ is the bulk coefficient for the heat flux at $10 \mathrm{~m}$ height and is taken as $1.24 \times 10^{-3}$ (according to Kondo, 1975), $U_{10}$ is the mean wind speed at $10 \mathrm{~m}$ height and derived by the relation (A.4) in Appendix 1 and $T_{s}$ is the mean temperature of surface water.

One of the simple and conventional methods to feature a dynamical effect of water surfaces on overlying winds is a relation of mean winds vs drag coefficients. Then also calculated were the drag coefficients of water surface and $U_{10}$, 
but a discussion on their relation will be left to Appendix 1.

All these parameters are averages over 410 seconds. Some of them were derived from the results of spectral analyses, the details of which will be described in the succeeding chapters.

\subsection{Summary of the selected data}

More than 500 records of data collected through several field experiments operated by the personnel of Ocean Research Institute, University of Tokyo during 8 years from 1967 to 1975 were analyzed and classified by the basic statistical parameters. They distribute over wide ranges of each parameter.

In order to solve the heart of question, a simplification of experimental conditions under which the data were obtained was needed. Hence further selection of the records was made according to the following conditions.

1) Time series of each channel of a record can be regarded as stationary (the tail end of an auto-correlation function tends to zero).

2) Swells propagate nearly parallel to winds (direction differences are within $\pm 22.5^{\circ}$ ).

3) Thermal stratifications of the atmospheric surface layer are near neutral $(|z / L|<0.1)$.

Forty-seven over-sea records satisfying the above three conditions were selected for the main body of data provided for further analyses and interpretations. Besides these data, those of three other categories were chosen for reference; eighteen over-lake records gathered under similar conditions of wind speeds, thermal stratifications and anemometer heights to those of the selected over-sea records were provided for a comparison of wave conditions; one over-sea record under unstable and thirteen over-sea under stable conditions were provided for inquiring the effects of thermal stratifications on spectra. Total number of the selected records of these four categories is seventy-nine.

The selected near-neutral, over-sea records distribute in the ranges from $1.3 \mathrm{~m} / \mathrm{s}$ to $8.5 \mathrm{~m} / \mathrm{s}$ of wind speeds and from $0.4 \mathrm{~m}$ to $4.0 \mathrm{~m}$ of anemometer heights. An inventory of all the selected records with their main basic parameters is given in Appendix 2.

\section{Spectral analyses and results}

\subsection{Procedure of analyses}

Spectral analyses were carried out using Tukey's method in which the spectral and cross-spectral density functions were defined by Fourier trans- forms of the auto-correlation and cross-correlation functions, respectively.

The relations of transformation for two time series records $x(t)$ and $y(t)$ are as follows.

$$
\begin{aligned}
& S_{x}(n)=\int_{0}^{\infty} r_{x}(\tau) \cos 2 \pi n \tau d \tau, \quad 0 \leq n<\infty \\
& S_{y}(n)=\int_{0}^{\infty} r_{y}(\tau) \cos 2 \pi n \tau d \tau, \quad 0 \leq n<\infty \\
& C_{x y}(n)=\frac{1}{2} \int_{0}^{\infty}\left\{r_{x y}(\tau)+r_{y x}(\tau)\right\} \cos 2 \pi n \tau d \tau, \\
& 0 \leq n<\infty \\
& Q_{x y}(n)=\frac{1}{2} \int_{0}^{\infty}\left\{r_{x y}(\tau)-r_{y x}(\tau)\right\} \sin 2 \pi n \tau d \tau, \\
& 0 \leq n<\infty
\end{aligned}
$$

where

$$
\begin{aligned}
& r_{x}(\tau)=\lim _{T \rightarrow \infty} \frac{1}{T} \int_{0}^{T} x(t) x(t-\tau) d t, \\
& r_{y}(\tau)=\lim _{T \rightarrow \infty} \frac{1}{T} \int_{0}^{T} y(t) y(t-\tau) d \tau, \\
& r_{x y}(\tau)=\lim _{T \rightarrow \infty} \frac{1}{T} \int_{0}^{T} x(t) y(t-\tau) d t,
\end{aligned}
$$

and

$$
r_{y x}(\tau)=\lim _{T \rightarrow \infty} \frac{1}{T} \int_{0}^{T} y(t) x(t-\tau) d t,
$$

and where $n$ is the frequency and $\tau$ is the time lag.

$S_{x}(n)$ and $S_{y}(n)$ are the spectral density functions of $x(t)$ and $y(t)$, respectively. $C_{x y}(n)$ is the real part and $Q_{x y}(n)$ is the imaginary part of the cross-spectral density function $S_{x y}(n)$ between $x(t)$ and $y(t)$, and are called the cospectral and the quadrature-spectral density functions, respectively. $r_{x}(\tau)$ and $r_{y}(\tau)$ are the auto-correlation functions of $x(t)$ and $y(t)$, respectively, and $r_{x y}(\tau)$ is the positive and $r_{y x}(\tau)$ is the negative cross-correlations between $x(t)$ and $y(t)$. The plots of these functions are called a spectrum, a cospectrum, a quadrature-spectrum, a autocorrelogram and a cross-correlogram, respectively.

These spectral and correlation functions have the following relations with those statistical parameters which were calculated in Chapter II.

Variance :

$$
\left.\begin{array}{l}
\overline{x^{2}}=\int_{0}^{\infty} S_{x}(n) d n=r_{x}(0) \\
\overline{y^{2}}=\int_{0}^{\infty} S_{y}(n) d n=r_{y}(0)
\end{array}\right\}
$$


Covariance :

$$
\overline{x y}=\int_{0}^{\infty} C_{x y}(n) d n=r_{x y}(0)
$$

The definitions on spectral functions demonstrated here should be noted for the quantitative discussions of spectral analyses which will be made in the later sections.

On practicing the spectral estimations for time series records of discrete sampling and of finite length, an algorithm used in Munk et al. (1959) was applied in this study.

In this algorithm, all Fourier transforms were with respect to correlation functions multiplied by a weighting function $(1+\cos \pi \tau / \tau \max )$ which converts abrupt ends of the correlation function occurring because of a finite length of the time series record into smooth die-aways.

The computational conditions were equal for every record. The sampling time interval $\Delta t$ was $0.2 \mathrm{sec}$. The number of data points of each channel of a record $\mathrm{N}$ was 2048 (corresponding to the data length of $410 \mathrm{sec}$ ) and the maximum lag number $m$ was 100 (corresponding to the maximum time lag of $20 \mathrm{sec}$ ). The resultant frequency resolution and frequency range were $0.025 \mathrm{~Hz}$ and 0 to $2.5 \mathrm{~Hz}$, respectively.

$(2 \mathrm{~N} / \mathrm{m}-1 / 2)$ gives an effective number of the degree of freedom which determines confidence limits of spectral estimates of a random variable. The present condition yields a degree of freedom of 40. Ninety-five percent confidence limits for a spectral estimate are given in Munk et al. (1959) as a function of the degree of freedom. According to it, the degree of freedom of 40 indicates that there are nineteen chances in twenty that the true spectral density lies within the range between 0.65 and 1.66 times an estimated value.

The length of selected records was limited because of eliminations of the parts contaminated by erroneous noises and unremovable trends, but is considered to meet the minimum requirements of the spectral analysis for this study.

The confidence limits are an indicator for the possible random errors attending spectral estimates. In addition, the present spectral analyses by the above procedure will be accompanied by some systematic errors (Munk et al. 1959). They are the errors due to the finite resolution, to the end effect of a finite record length, to the side band and to the descrete sampling.

The finite resolution and the end effect may add a considerable amount of erroneous energy to the lowest range of spectra, when the record involves a trend or a rather small amplitude fluctuation of a frequency lower than the computed lowest frequency point. The spectral component of a low energy level in the vicinity of peaking ones will be contaminated by the side band of the peaking components. As a low-pass filter with a sharp cut-off curve will reduce effectively the spectral energy higher than the cut-off frequency, an aliasing error due to the discrete sampling will be small. Order estimations of the errors were made for each spectral function of every record.

A problem on interactions between winds and waves may usually be treated as a two-dimensional problem in a plane parallel to the longitudinal $(x)$ direction and to the vertical $(z)$ direction, assuming that both waves and airflows propagate toward the same direction, and that in the lateral direction both wind and wave fields are statistically homogeneous. In present study, this approach may be acceptable, as the data were selected so that they might fit to the above assumptions. Therefore, all the further analyses on the wind fields are made for two-dimensional wind velocity fluctuations of $u$ and $w$ components.

With these considerations the spectra of $u$ component $S_{u}(n)$, of $w, S_{w}(n)$ and of $\zeta, S_{\zeta}(n)$, the cospectra between $u$ and $w, C_{u w}(n)$, between $u$ and $\zeta, C_{u \zeta}(n)$ and between $w$ and $\zeta, C_{w \zeta}(n)$ and the quadrature spectra between $u$ and $w, Q_{u w}(n)$, between $u$ and $\zeta, Q_{u \zeta}(n)$ and between $w$ and $\zeta$, $Q_{w \zeta}(n)$ were estimated from the processed data records.

\subsection{Broad features of the measured spectra}

In Fig. 1 a set of typical examples of measured logarithmic spectra are shown. The upper three spectra in the figure are the spectra of $u, w$ and $\zeta$ respectively obtained from an over-sea record, and the lower are those from an over-lake record.

A clear difference is seen between the wave spectra of these two records. In case of the oversea record the wave spectrum have two major peaks, one in a lower frequency region and another in a higher region. The peak at the lower frequency region may be corresponding to swells and is predominant over entire frequency range (see Fig. 1a).

On the other hand, a wave spectrum over lake does not have any predominant peak in its lower frequency region. Such swell-corresponding peaks 
(a)

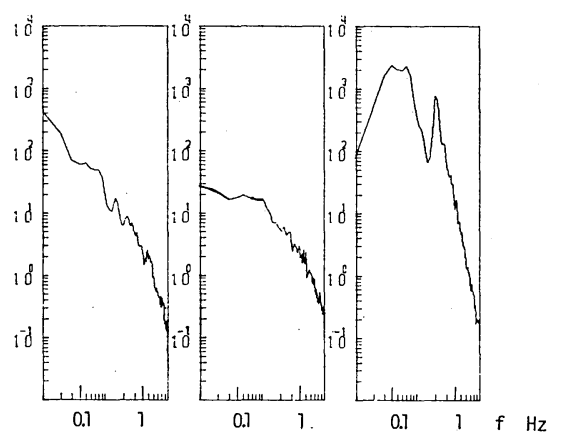

Rec. No.942-2( HIRATSUKA TOWER ): $z=400 \mathrm{~cm}, U=491 \mathrm{~cm} / \mathrm{s}$

(b)

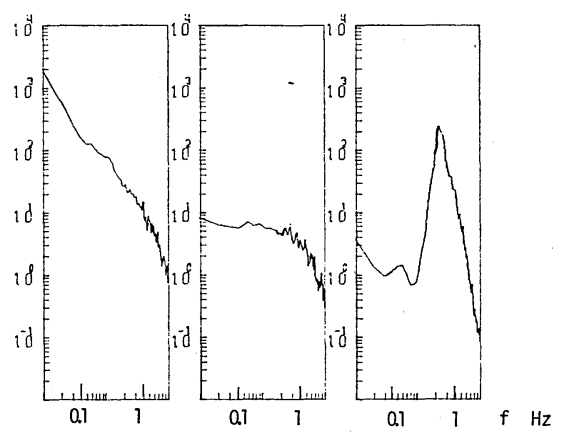

Rec. No.103-2L( LAKE KASUMIGA-URA ): $z=70 \mathrm{~cm}, U=515 \mathrm{~cm} / \mathrm{s}$

Fig. 1 Typical examples of logarithmic spectra of $u$. $w$ and $\zeta$. (a) from an over-sea record: Rec. No. 942-2 (b) from an over-lake record: Rec. No. 103-2L: the ordinate of each figure is of arbitrary scaling.

in over lake wave spectra often become obscure, while peaks corresponding to wind waves are distinguished as well as those of over-sea spectra (see Fig. 1b).

In both cases, wave spectra in the frequency range higher than a frequency of a wind wave peak were very similar to each other and almost obey the $n^{-5}$ law of the equilibrium range of wind wave spectra (Phillips, 1977).

Most swell peaks lie in a frequency range of $0.1-0.125 \mathrm{~Hz}$, clearly separated from the wind wave peaks, and lie much beneath the $n^{-5}$ curve extended from the equilibrium range. This fact will suggest that these swells were at the decaying stage and were not directly related to the winds right there. Wind wave peaks will come out around $0.3 \mathrm{~Hz}$ when $U_{10}=6 \mathrm{~m} / \mathrm{sec}$, and are shifted toward a higher frequency region with a decreasing wind speed.

The foregoing parameters $c_{1}, c_{2}$ (see Section 2.4) denoting the phase velocities of these distinctly peaking components of a wave spectrum calculated by the dispersion relation of gravity waves with a consideration of the water depth (the smaller suffix number corresponds to the peaking component of the higher spectral density). These phase velocities will simply indicate the spectral difference of wave conditions of water surfaces.

The spectra of $u$ and $w$ at a higher frequency range are smooth and follow the curve of $n^{-5 / 3}$ which is expected from Kolmogoroff's hypothesis for the spectrum of the inertial subrange of isotropic turbulence, but in the lower frequency range, the wind spectra will have much irregularities with some peaks at frequencies where the wave spectra have peaks. Further investigations on the measured wind spectra are left to the following chapters.

\subsection{Normalized spectra and cospectra of wind velocity fluctuations}

The similarity theory predicts existence of a universal spectrum of turbulent fluctuations in the atmospheric surface layer (Monin and Obukhov, 1954). A large integration of empirical knowledge collected over land in the framework of the similarity theory has verified the prediction of the universal spectrum (Lumley and Panofsky, 1964).

The universal form for a wind velocity spectrum will be obtained when a spectrum is normalized by a dimensionless frequency $f$ and $a$ dimensionless spectral density $\Phi$ with a parameter $z / L$, where $f=n z / U$ and $\Phi=n S(n) / u *^{2}$ (Lumley and Panofsky, 1964).

The measured spectra were normalized in this manner and composed by superposing all the individual spectra in each group separated by four categories (see Section 2.4), and by bandaveraging with $f$ so that the final estimates were obtained at ten points per decade of $f$.

Logarithmic plots of normalized $u$ and $w$ spectra of band averaged composites from fortyseven over-sea near-neutral records are illustrated by open circles in Figs. $2 a$ and $2 b$. Confidence limits for each plot are indicated by a segment.

Also drawn are curves of model spectra in neutral condition $(z / L=0)$ proposed by Kaimal et al. (1972), ' $\mathrm{K}$ ', and Busch (1973), 'B', in the same figures. Differences due to the thermal stabilities $z / L=-0.1$ (unstable) and $z / L=0.1$ (stable) in Kaimal's spectrum are shown by dashed curves.

Among several model curves for the universal 


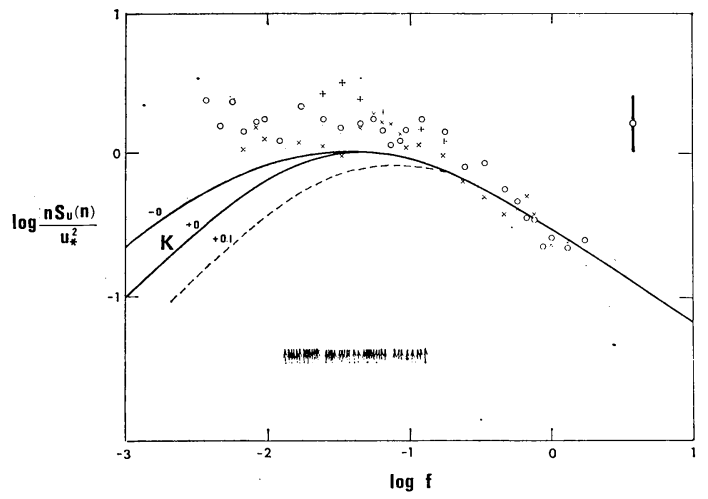

Fig. 2(a) Normalized spectra of wind velocity fluctuations over sea ( $u$-component), in neutral air $(O)$, in stable air $(X)$ and in unstable air $(+)$, together with model spectra by Kaimal et al. (1972) for neutral air (solid line) and for stable air of $z / L=+0.1$ (broken line). The vertical segment indicates the range of confidence limits for each plot. Small arrows show the frequencies of the highest peak in each wave spectrum.

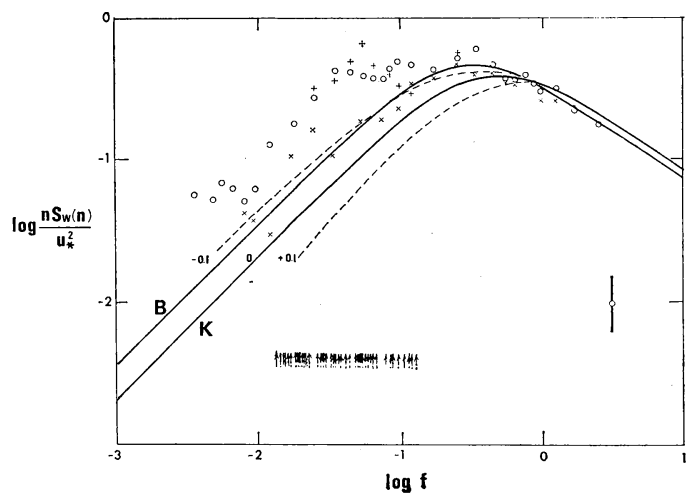

Fig. 2(b) Normalized spectra of wind velocity fluctuations over sea ( $w$-component), in neutral air $(O)$, in stable air $(X)$ and in unstable air $(+)$, together with model spectra for neutral air by Kaimal et al. (1972) (solid line labeled ' $K$ ') and and by Busch (1973) (solid line labelde ' $B$ '), for stable air of $z / L=+0.1$ and for unstable air of $z / L=-0.1$ (broken lines) by Kaimal et al. (1972). The vertical segment indicates the range of confidence limits for each plot. Small arrows show the frequencies of the highest peak in each wave spectrum.

spectrum proposed by various investigators, those by Kaimal et al. (1972) and by Busch (1973) are considered as typical models derived by summarizing a large number of data elaborately collected through field observations over land and are considered to be reliable ones though they are slightly deviated each other.
Comparing the present results of over-sea observations with these model spectra, it is found that there are apparent disagreements in the frequency range around the peaks and of the lower sides of it.

In these frequency range, the measured oversea spectra of both $u$ and $w$ deviate toward larger spectral density values from the model spectra, while in higher frequency ranges the measured ones almost lie on the model curves.

In the same figures, normalized spectra in the stable and unstable air are plotted for reference by $\times$ and + marks, respectively in the same manner as the neutral spectra. They show upward deviations from the corresponding model spectra as well as the near-neutral spectra.

The behavior of the major parts of the deviation cannot be attributed to such errors originated in the processes of the experiments and computations as mentioned in Section 3.1.

Small arrows below the plots and the curves in Figs. $2 a$ and $2 b$ show the corresponding frequencies of the highest peak in each wave spectrum. It is suggestive that major deviations occur in the frequency region where the arrows appear.

The deviations are very similar to those reported by Busch and Panofsky (1968). Fig. 3 is a citation from Fig. 16 of their paper in which the comparison of over-sea spectra of $u$ and $w$ with those over-land was attempted and consequently the distinctive difference was suggested. The present results will confirm their suggestion.

Meanwhile normalized over-lake spectra of $u$ and $w$ are almost coincident with the corresponding model spectra in the middle and high fre-

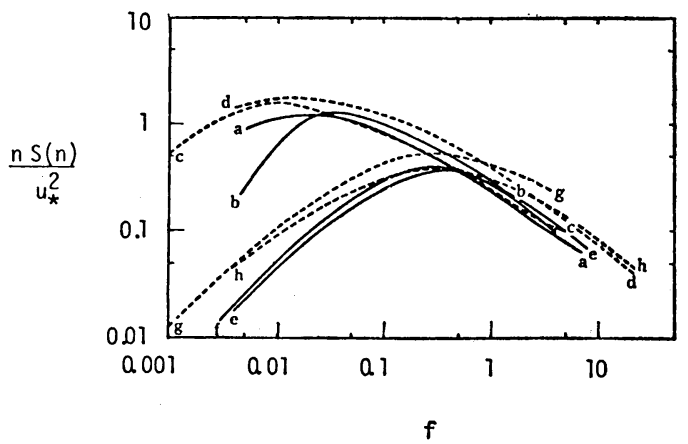

Fig. 3 Comparison of spectra over land and sea by Busch and Panofsky (citation of Fig. 16 of Busch and Panofsky, 1968). $u$-component; a, b, over land, c, over sea (Smith, 1967), d, over sea (Weiler and Burling, 1967), w-component; e, f, over land, g, over sea (Smith), and h, over sea (Weiler and Burling). 


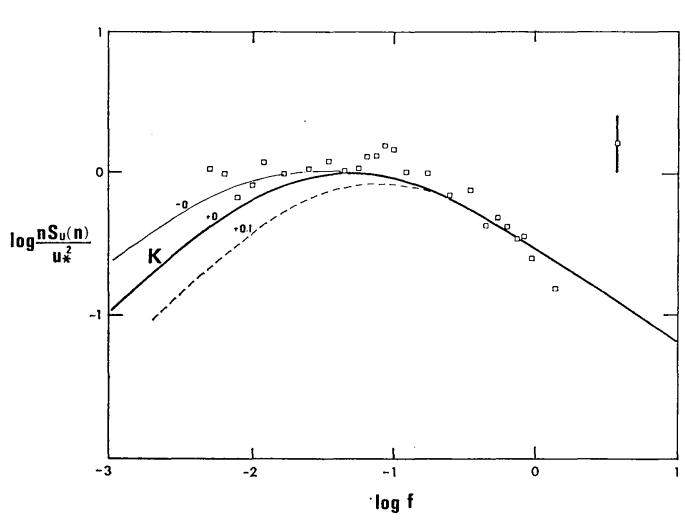

Fig. 4(a) Normalized spectra of wind velocity fluctuations over lake ( $u$-component, $\square)$, together with the model spectra drawn in the same manner as in Fig. 2(b).

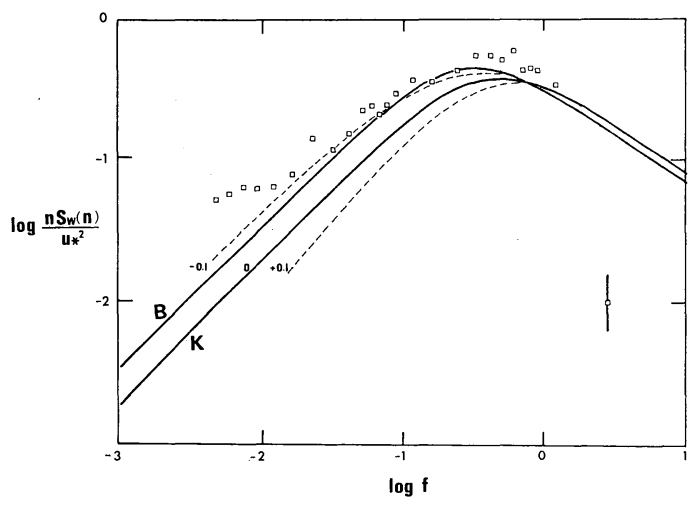

Fig. 4(b) Normalized spectra of wind velocity fluctuations over lake ( $w$-component, $\square)$, together with the model spectra drawn in the same manner as in Fig. 2(b).

quency ranges and have little deviation from them, respectively, as shown in Figs. $4 a$ and $4 b$.

On the cospectrum between fluctuating wind components in the surface boundary layer, also predicted are universal forms from the similarity arguments. In Fig. 5 is shown a logarithmic over-sea $u-w$ cospectrum normalized by the dimensionless frequency $f=n z / U$ and the dimensionless cospectral density $n C_{u w}(n) / U *^{2}$ and composed in the same manner as the normalized spectra of $u$ or $w$. The plot of the cospectrum appears to show a fairly good agreement with a generalized model of $u-w$ cospectrum given by Kaimal et al. (1972) which is illustrated in the same figure. The behavior of over-lake cospectrum is much the same as that of over-sea spectrum. This $u-w$ cospectral behavior of oversea observation looks rather curious in contrast

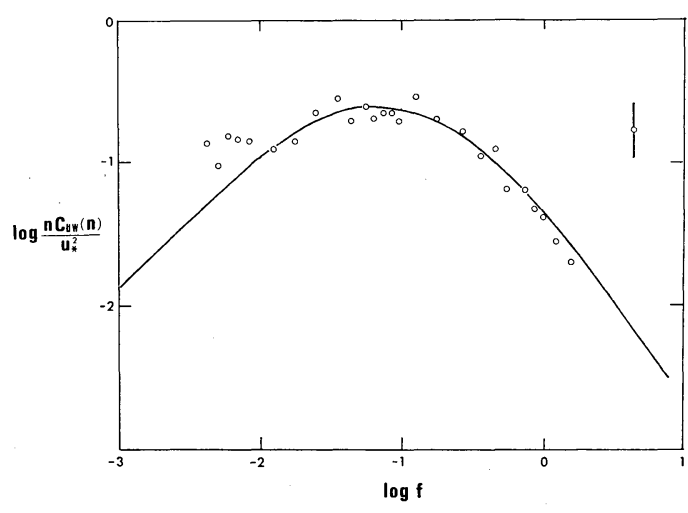

Fig. 5 Normalized cospectra between $u$ and $w$ components of wind velocity fluctuations over sea, in netural air $(\mathrm{O})$, together with a cospectral curve for neutral air by Kaimal et al. (solid line). The segment indicates the range of confidence limits for each plot.

with those of over-sea spectra of $u$ and $w$ which indicate significant descrepancies against the reported model spectra.

As seen in this chapter, the results of spectral analyses suggest that the behaviors of spectra of wind velocity fluctuations over waters depend much on the spectral difference of wave fields of water surfaces, while the behaviors of $u-w$ cospectra are almost unchanged against changing spectral modes of underlying waves and are very similar to those of the model cospectrum. More directly, the results show that anomalous deviations occur in the lower frequency range of the normalized spectra of $u$ and $w$, when the wave spectra have a predominant peak in the lower frequency range or in the swell region.

\section{Coherence function and wave coherent perturbations in winds}

\subsection{Coherence function}

In order to specify correlations between wind velocity fluctuations and underlying waves, coherence functions between $u$ and $\zeta, R_{u \zeta}$ and between $W$ and $\zeta, R_{w \zeta}$ were computed from the spectra, cospectra and quadrature-spectra obtained in Chapter 3.

A coherence function between two time series records $x(t)$ and $y(t), R_{x y}(n)$ is defined in term of foregoing notations by

$$
R_{x y}(n)=\frac{C_{x y}^{2}(n)+Q_{x y}^{2}(n)}{S_{x}(n) S_{y}(n)}
$$

The physical meaning of the coherence is as follows. If a linear system exists between two 
time series signals $x(t)$ and $y(t)$ (either of them is the input and other is the output) and no noise contaminates each of them, then the coherence $R_{x y}(n)$ is equal to unity, and if either or both of them have any noises (which include non-linear output signals), $R_{x y}(n)$ takes a value between 0 and 1 (Bendat and Piersol, 1971).

By the way, another function relevant to joint properties of two time series is defined here by

$$
\theta_{x y}(n)=\tan ^{-1} \frac{Q_{x y}(n)}{C_{x y}(n)} .
$$

$\theta_{x y}(n)$ is called the phase difference which means a difference of phase angle between Fourier components of the same frequency of two records $x(t)$ and $y(t)$. In this case $\theta(n)$ is the phase lead of the $y$-record relative to the $x$-record. The phase differences will be applied for discussions in the succeeding chapter.

Confidence limits of the coherence function can be obtained from the relations 6.112 of Bendat and Piersol (1971). At least, a coherence greater than 0.45 may be regarded as to be significant when the degree of freedom is 40 . Confidence limits of the phase difference depend on the coherence.

Fig. 6a shows the frequency distributions of $R_{u \zeta}(n)$ (upper figure) and $R_{w \zeta}(n)$ (lower) computed from the over-sea records. Each graph of the figure is a composite of the coherence plots of forty-seven individual records.

From this figure broad features of the coherence functions for the over-sea records can be well grasped. $\boldsymbol{R}_{w \zeta}(n)$ has predominant peaks in the lower frequency region around $0.1 \mathrm{~Hz}$, where spectral peaks due to swells appear in a wave spectrum, and some of the peaks have values close to unity. But in the higher frequency region $R_{w}$ is reduced below 0.4 except around the frequencies where peaks due to wind waves come out.

$\boldsymbol{R}_{u \zeta}(n)$ has a similar tendency to $\boldsymbol{R}_{w \zeta}(n)$ but is somewhat less than $R_{w \zeta}$ in the entire frequency range except for values around peaking frequency of wind waves. The maxima of $R_{u \zeta}$ also appear in the swell region and their values seldom go up beyond 0.8 .

Fig. $6 \mathrm{~b}$ illustrates the frequency distributions of $\boldsymbol{R}_{u \zeta}(n)$ and $\boldsymbol{R}_{w \zeta}(n)$ for the over-lake records in the same manner as Fig. 6a. This result features that neither $\boldsymbol{R}_{u \zeta}$ nor $\boldsymbol{R}_{w \zeta}$ has any significant peaks in the lower frequency region.

After all, the results of coherence analyses show that there are significant coherences be-
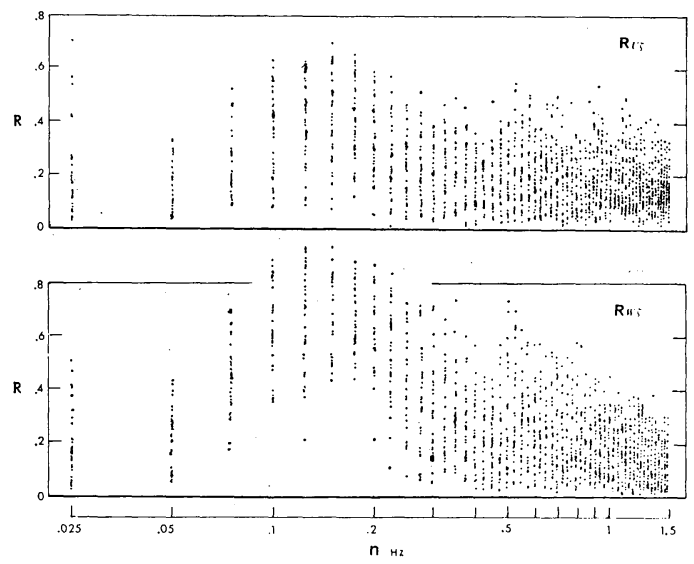

Fig. 6(a) Frequency distribution of the coherence between waves and wind fluctuations observed over sea. The upper figure; $R u \zeta$, the lower; $R w \zeta$.
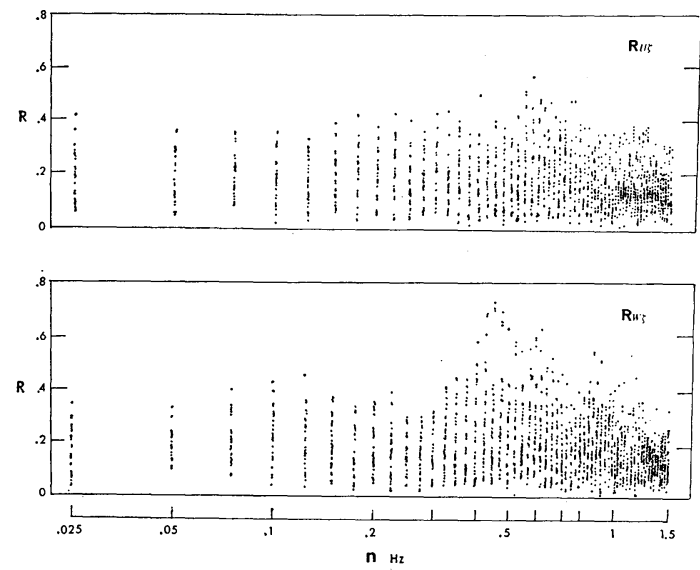

Fig. 6(b) Frequency distribution of the coherence between waves and wind velocity fluctuations observed over lake. The upper figure; $R u \zeta$, the lower; $R w \zeta$.

tween wind velocity fluctuations and underlying waves over the frequency ranges where wave spectra have large values around their peaks.

\subsection{Spectral estimation of wave coherent perturbations in winds}

That a coherence function has a finite value between 0 and 1 implies that the wind velocity fluctuations over water waves contain perturbations which are outputs of a possible linear system with inputs of waves as mentioned above.

Here the perturbation is referred to a wave coherent perturbation and it's $x$ and $z$ components are denoted by $\ddot{u}$ and $\tilde{w}$, respectively. Then the time series records $u(t)$ and $w(t)$ may be written 
as

$$
\begin{aligned}
& u(t)=U+u^{\prime}(t)+\tilde{u}(t) \\
& w(t)=w^{\prime}(t)+\tilde{w}(t)
\end{aligned}
$$

where $u^{\prime}$ and $w^{\prime}$ are the turbulent components in wind velocity fluctuations. The turbulent components should be incoherent with the waves and consequently with the wave coherent perturbations.

Now the spectral estimates of $\tilde{u}, S_{\tilde{u}}(n)$ can be computed by the following way. A spectrum of $u(t)$ in terms of the expression (4.3) and a spectrum of waves $\zeta(t)$ are given by

$$
\begin{aligned}
& S_{u}(n)=S_{u^{\prime}}(n)+S_{\tilde{u}}(n) \\
& S_{\zeta}(n)=S_{\zeta}(n) .
\end{aligned}
$$

Also given is a cross-spectrum between $u(t)$ and $\zeta(t)$ by

$$
S_{u \zeta}(n)=S_{u^{\prime} \zeta}(n)+S_{\tilde{u} \zeta}(n)=S_{\tilde{u} \zeta}(n)
$$

as

$$
S_{u^{\prime} \zeta}(n)=0
$$

where

$$
S_{u \zeta}(n)=C_{u \zeta}(n)+i Q_{u \zeta}(n) \quad \text { (see Section 3.1). }
$$

Substitution of (4.5), (4.6) and (4.7) into (4.1) gives the coherence between $u(t)$ and $\zeta(t)$

$$
\begin{gathered}
R_{u \zeta}(n)=\frac{S_{u \zeta^{2}(n)}}{S_{\zeta}(n) S_{u}(n)}=\frac{S_{\tilde{u} \zeta^{2}}(n)}{S_{\zeta}(n)\left\{S_{u^{\prime}}(n)+S_{\tilde{u}}(n)\right\}} \\
=\frac{R_{\tilde{u} \zeta}(n)}{1+S_{u^{\prime}}(n) / S_{\tilde{u}}(n)}
\end{gathered}
$$

According to the definition of $\tilde{u}(t)$,

$$
R_{\tilde{u} \xi}(n)=1
$$

Hence from (4.8) together with (4.9), $S_{\tilde{u}}(n)$ is given by

$$
\begin{aligned}
S_{\tilde{u}}(n) & =R_{u \xi}(n)\left\{S_{\tilde{u}}(n)+S_{u^{\prime}}(n)\right\} \\
& =R_{u \zeta}(n) \cdot S_{u}(n)
\end{aligned}
$$

In the same way, the spectral estimates of $\tilde{w}$, $S_{\tilde{w}}(n)$ are computed by

$$
S_{\tilde{w}}=R_{w \zeta}(n) \cdot S_{w}(n)
$$

In the succeeding arguments, the spectra of wave coherent perturbations $S_{\tilde{u}}$ and $S_{\tilde{w}}$ are defined and evaluated by (4.10) and (4.11) respectively, apart from questions of the confidence limits of $S_{u}, S_{w}, R_{u \zeta}$ and $R_{w \zeta}$.

A cospectrum between $\tilde{u}$ and $\tilde{w}, C_{\tilde{u} \tilde{w}}$ is interesting in relation to momentum transfer by the wave coherent perturbations. The cospectrum $C_{\tilde{u} \tilde{w}}$ will be given by

$$
C_{\tilde{u} \tilde{w}}(n)=\frac{C_{u \zeta}(n) C_{w \zeta}(n)+Q_{u \zeta}(n) Q_{w \zeta}(n)}{S_{\zeta}(n)}
$$

as Benilov et al. (1974) showed.

The method of spectral and cospectral estimations of the wave coherent perturbations by the relations (4.10), (4.11) and (4.12) were used by Benilov et al. (1974). Ichikawa and Imasato (1976) also used the same relations as (4.10) and (4.11) for evaluation of wave induced fractions in the wind spectra over water surfaces.

\subsection{Separation of contributions of wave coherent perturbations from normalized wind spectra and cospectra}

If the relations (4.3) and (4.4) are assumed, a spectrum of turbulent components in the wind velocity fluctuations $S_{u},(n)$ and $S_{w},(n)$ should be given from (4.4) by

$$
\begin{aligned}
& S_{u^{\prime}}(n)=S_{u}(n)-S_{\tilde{u}}(n) \\
& S_{w^{\prime}}(n)=S_{w}(n)-S_{\tilde{w}}(n)
\end{aligned}
$$

Hence, spectral contributions of the wave coherent perturbations $S_{\tilde{u}}(n)$ and $S_{\tilde{w}}(n)$ of the over-sea records were computed using (4.7) and (4.8), and were separated from the measured spectra $S_{u}(n)$ and $S_{w}(n)$ respectively. Figs. 7a and $7 \mathrm{~b}$ show composite normalized spectra of $u$ and $w$ excluding $S_{\tilde{u}}(n)$ and $S_{\tilde{w}}(n)$ respectively. In these figures, all other things but plots of the result are equal to those in Figs. $2 a$ and $2 b$.

The behaviors of both new spectra of $u$ and $w$ excluding $S_{\tilde{u}}(n)$ and $S_{\tilde{w}}(n)$ respectively, show clear differences from those of their original spectra in Figs. 2a and 2b. They turned out more smooth and less irregular than the original ones. In the middle and low frequency regions, the normalized spectral density values in both $u$ and $w$-spectra decreased distinctly by excluding of contributions of the wave coherent perturbations, and excepting in the lowest frequency region, the deviations of over-sea $w$-spectrum from the model spectrum practically vanished, while the new $u$-spectrum lies a little beneath the model spectral curve and is almost in parallel to it.

These resultant distributions of the spectra removing the contributions due to wave coherent perturbations are suggestive of systematic features very similar to the model spectra provided for turbulences in the surface layer. Although there are still a bit of disagreements with the models, the differences are comparable with those between the models.

As the values of coherence up to 0.9 indicate, the removed portions of $S_{\tilde{w}}(n)$ are not small and, particularly in the swell region, will take a greater part of a frequency component of a spectrum, 


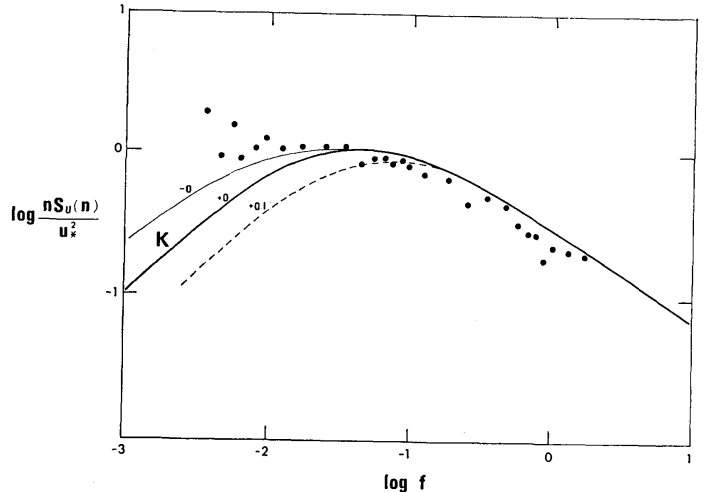

Fig. 7(a) Normalized spectra of wind velocity fluctuations over sea, excluding contribution of the wave coherent perturbations ( $u$-component, $\bullet$ ). Otherwise, same as Fig. 2(a).

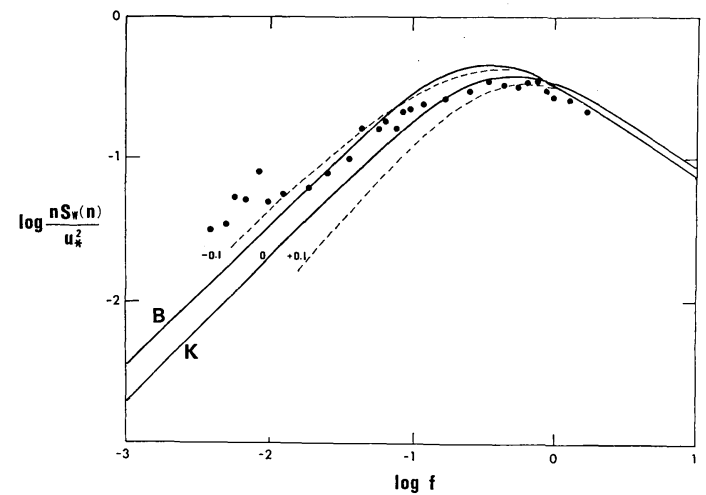

Fig. 7(b) Normalized spectra of wind velocity fluctuations over sea, excluding the contribution of wave coherent perturbations ( $w$-component, $\bullet$ ). Otherwise, same as Fig. 2(b).

whereas it looks not quite satisfied because of logarithmic plots. The situations of $S_{\tilde{u}}(n)$ are similar to those of $S_{\tilde{w}}(n)$ to a certain extent.

The same operation of separation of $S_{\tilde{u}}(n)$ and $S_{\tilde{w}}(n)$ was made on the over-lake spectra for comparison. The results were shown in Figs. 8a and $8 \mathrm{~b}$ in the same manner as Fig. 4. In this case, the separation lessened irregularities which the original spectra had, but it little changed the spectral level.

Also made were removal of contribution of wave coherent perturbations from normalized cospectra between $u$ and $w$ collected over-sea using the relation (4.12). The results were plotted in Fig. 9 like Fig. 5. Although $C_{\tilde{u} \tilde{w}}(n)$ were excluded, the new cospectrum is almost the same as the original one in Fig. 5 and shows a

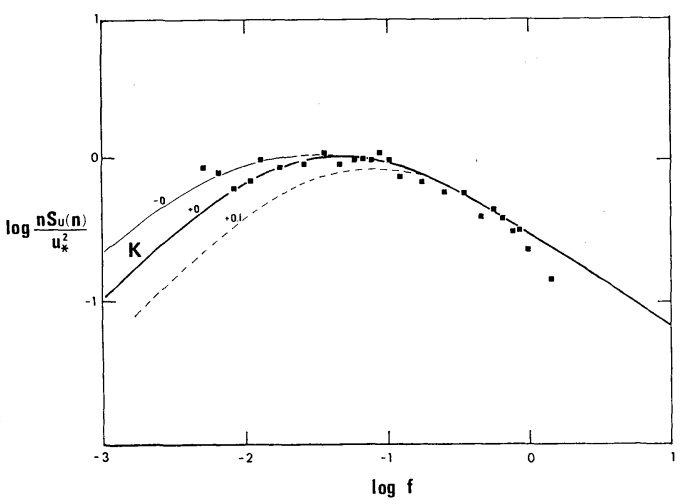

Fig. 8(a) Normalized spectra of wind velocity fluctuations over lake excluding the contribution of wave coherent perturbations ( $u$-component, $\mathbf{\square}$ ). Otherwise, same as Fig. 2(a).

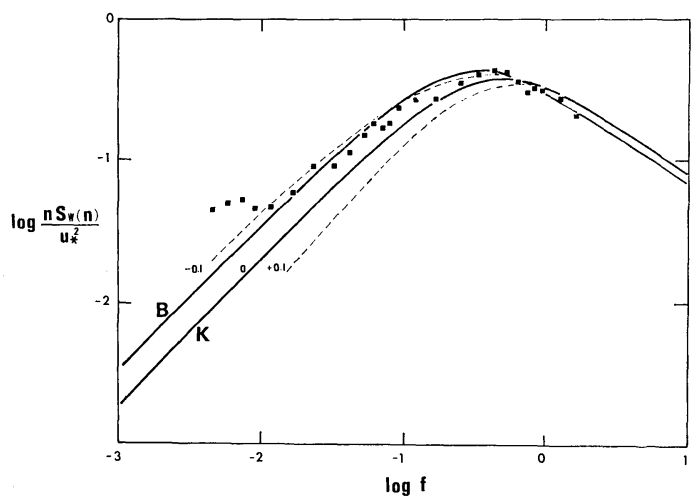

Fig. 8(b) Normalized spectra of wind velocity fluctuations overlake, excluding the contribution of wave coherent perturbations ( $w$-component, $\mathbf{\square})$. Otherwise, same as Fig. 2(b).

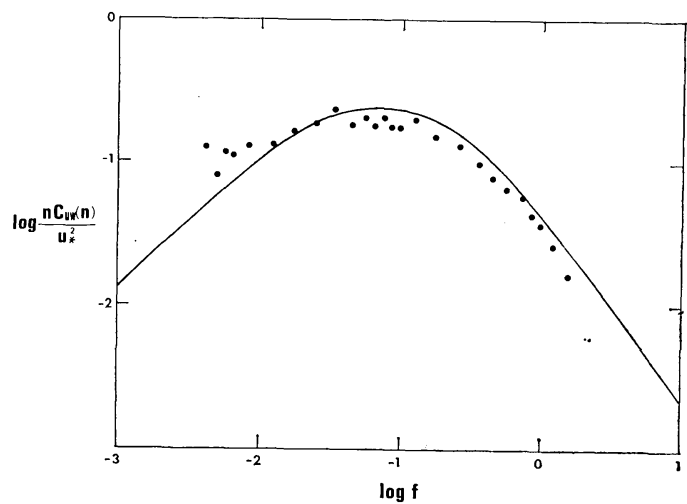

Fig. 9 Normalized cospectra between $u$ and $w$-components of wind velocity fluctuations over sea, excluding the contribution of wave coherent perturbations (๑). Otherwise, same as Fig. 5. 
more smooth distribution than it.

It is recognized through the analyses in this chapter that the wave coherent perturbations surely exist in the winds over sea and if their linear additions to turbulences can be assumed, they may quantitatively be interpreted the deviations of over-sea spectra from the model spectra which the similarity criterion can hardly interpret.

The wave coherent perturbation seems to be large at a frequency where underlying swell has a large spectral density and to contribute much to spectra and little to cospectra. These natures of the perturbation will be detailed in the succeeding chapter.

\section{Frequency response functions}

\subsection{Computation of frequency response functions}

In this chapter, nature of the wave coherent perturbations separated from wind fluctuations over the sea are investigated by means of frequency response functions of the expected linear system connecting the coherent perturbations and waves, with parameters of wind speeds and anemometer heights. Thereby it will be solved that what conditions make the perturbations grow up.

When two time series records $x(t)$ and $y(t)$ are the input and output of a linear system respectively, a frequency response function $H_{x y}(n)$ is defined in terms of the foregoing notations by

$$
S_{x y}(n)=H_{x y}(n) S_{x}(n)
$$

where $S_{x y}(n)$ is a cross-spectrum and is related by

$$
S_{x y}(n)=C_{x y}(n)+i Q_{x y}(n)
$$

$H_{x y}(n)$ can be written by

$$
\boldsymbol{H}_{x y}(n)=\left|\boldsymbol{H}_{x y}(n)\right| \exp \left[-i \phi_{x y}(n)\right]
$$

where

$$
\left|H_{x y}(n)\right|=\sqrt{S_{y}(n) / S_{x}(n)}
$$

and

$$
\phi_{x y}(n)=\theta_{x y}(n)
$$

$\left|H_{x y}(n)\right|$ is called a system gain factor and $\phi_{x y}(n)$ is called a system phase factor. A frequency response function, therefore, is expressed by these two factors (Bendat and Piersol, 1971).

Taking $x(t)=\zeta(t)$ and $y(t)=\tilde{u}(t)$ or $\tilde{w}(t)$, $\left|H_{\zeta \tilde{u}}(n)\right|,\left|H_{\zeta \tilde{w}}(n)\right|, \phi_{\zeta \tilde{u}}(n)$ and $\phi_{\zeta \tilde{w}}(n)$ are computed for every record measured over sea using relations (3.1), (3.2), (4.2), (5.2) and (5.5).

\subsection{Behaviors of frequency distributions of gain} factor

Dimensionless gain factors $\mid\left(H_{\zeta \tilde{u}}(n) \mid / n\right.$ and $\left|H_{\zeta \tilde{w}}(n)\right| / n$ were plotted against a dimensionless frequency $2 \pi U n / g$ where $U$ is a mean wind speed at the anemometer height, and $g$ is the gravitational acceleration. The dimensionless gain factors $\left|H_{\zeta \tilde{u}}\right| / n$ and $\left|H_{\zeta \tilde{w}}\right| / n$ correspond to ratios of the amplitudes of a frequency component of the perturbation velocities $\tilde{u}$ and $\tilde{w}$ to that of the orbital velocity of underlying water waves. The dimensionless frequency $2 \pi U n / g$ means a ratio of frequency to that of a wave component whose phase speed according to the dispersion relation of gravity waves is equal to the observed mean wind speed $U$. Hence $2 \pi U n / g>1$ loosely implies the frequency region of wind waves, and $2 \pi U n / g<1$ does that of swells.

The frequency distributions of dimensionless gain factors were composed by superposing of all plots of every record in a group separated by a parameter $z$, and by band-averaged in the same manner as the normalized spectra and cospectra.

Frequency distributions of the dimensionless gain factors $\left|H_{\zeta \tilde{u}}\right| / n$ and $\left|H_{\zeta \tilde{w}}\right| / n$ for $z=50,100$, 200 and $400 \mathrm{~cm}$ are shown in Figs. 10a and 10b, respectively. The group of records $z=50 \mathrm{~cm}$ includes those measured at $z=40-60 \mathrm{~cm}$. Similarly, the $z=100 \mathrm{~cm}$, the $z=200 \mathrm{~cm}$ and the $z=400 \mathrm{~cm}$ represent those at $z=90-120 \mathrm{~cm}$, at $z=190-200 \mathrm{~cm}$ and at $z=400 \mathrm{~cm}$, respectively. The total number of records of these four groups is thirty-nine. These figures show that behaviors of the frequency distributions of $\left|H_{\zeta \tilde{u}}(n)\right|$ are similar to those of $\left|H_{\zeta \tilde{w}}(n)\right|$. They have a remarkable change at a frequency around $2 \pi U n / g=1$. In the frequency region $2 \pi U n / g>1$, dimensionless gain factors fall much to lower levels of order of 0.1 , while in the region $2 \pi U n / g<1$, they lie on relatively high levels of $0.5-1$, where $\left|H_{\zeta \tilde{u}}\right|$ is :1-1.6 times as large as $\left|H_{\zeta \tilde{w}}\right|$. This fact would suggest that the perturbations are induced much more effectively by swells than by wind waves, and that the amplitude of $u$-component of the perturbation may be a little larger than that of $w$-component in the lower frequency region.

It should be noted that this behavior may be consistent with the results of Kondo et al. (1972) which were derived theoretically from the solutions of Orr-Sommerfeld equation describing the critical layer instability over waves.

According to the theory, an attenuation of the perturbation with exponential heights is expected. 


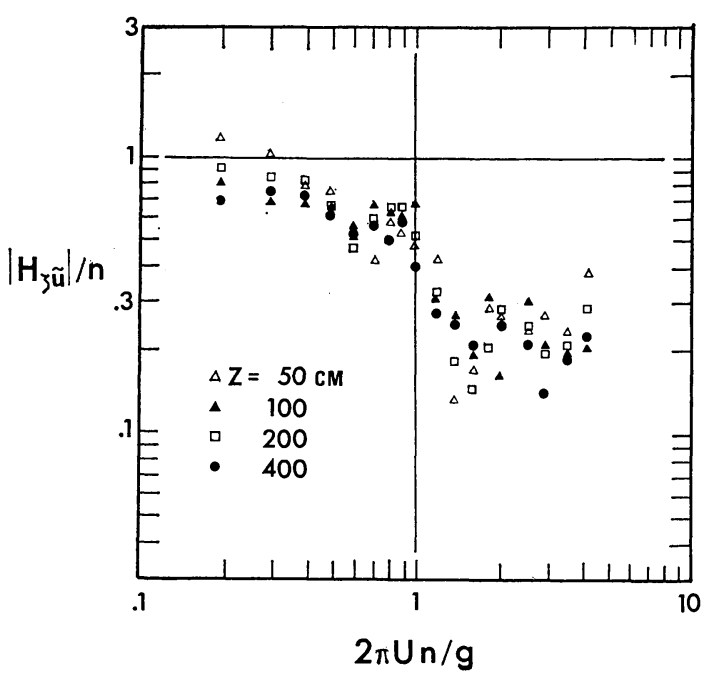

Fig. 10(a) Dimensionless gain factors between waves and wave coherent perturbations versus dimensionless frequency; cases between $u$ and $\zeta$ with parameter $z$.

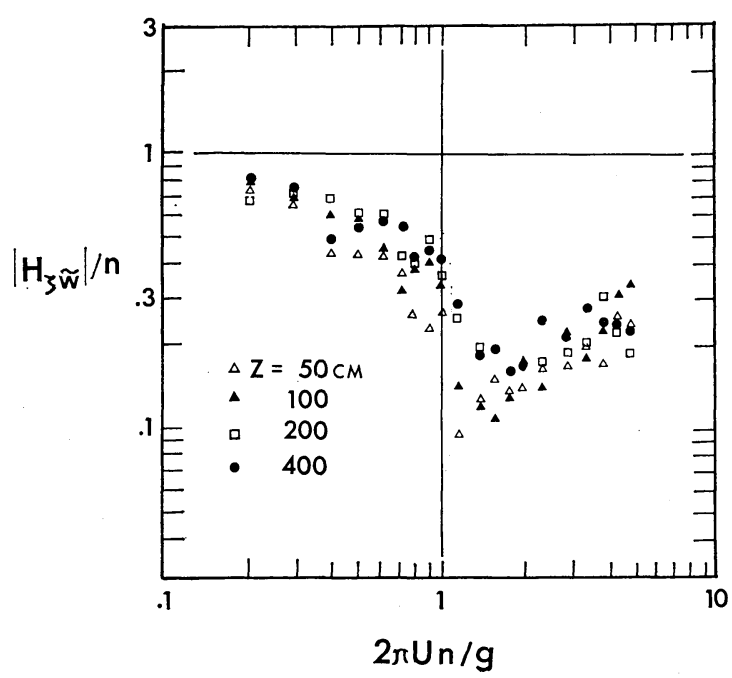

Fig. 10(b) Dimensionless gain factors between waves and wave coherent perturbations versus dimensionless frequency; cases between $w$ and $\zeta$ with the parameter $z$.

But as far as the present results indicate, dependence of the gain factor on the height is very small even if it exists, and it may be difficult to find out its attenuation rate with heights.

\subsection{Behaviors of frequency distributions of phase factor}

Computed phase factors were plotted against the dimensionless frequency $2 \pi U n / g$ and were composed simply by superposing all the plots in every group separated by anemometer heights. Resultant distributions for $z=50,100,200$ and $400 \mathrm{~cm}$ are given in Figs. 11a, 11b, 11c and 11d.

Here, again a discontinuous and critical behavior came out at the frequency around $2 \pi U n / g=1$ in the phase factor distribution of every height. In the frequency region $2 \pi U n / g<$ 1 , distribution of $\phi_{\zeta \tilde{u}}$ and $\phi_{\zeta \tilde{w}}$ are almost coincident with lines of $\phi=180^{\circ}$ and $\phi=-90^{\circ}$
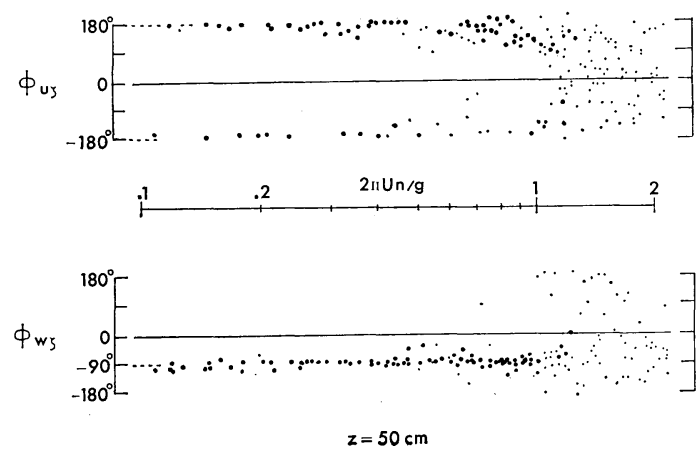

Fig. 11(a) Phase factors between waves and wave coherent perturbations versus dimensionless frequency; $z=50 \mathrm{~cm}$.
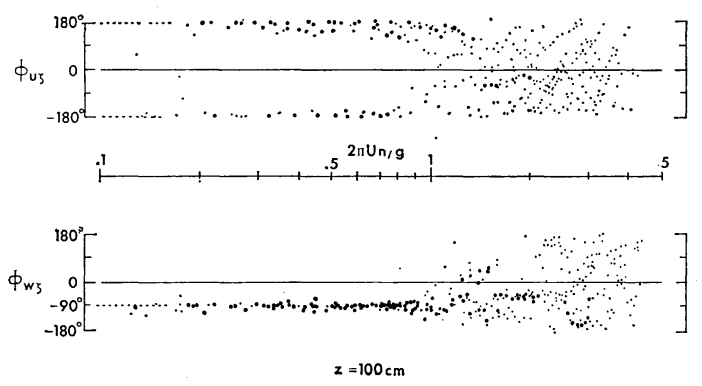

Fig. 11(b) Phase factors between waves and wave coherent perturbations versus dimensionless frequency; $z=100 \mathrm{~cm}$.
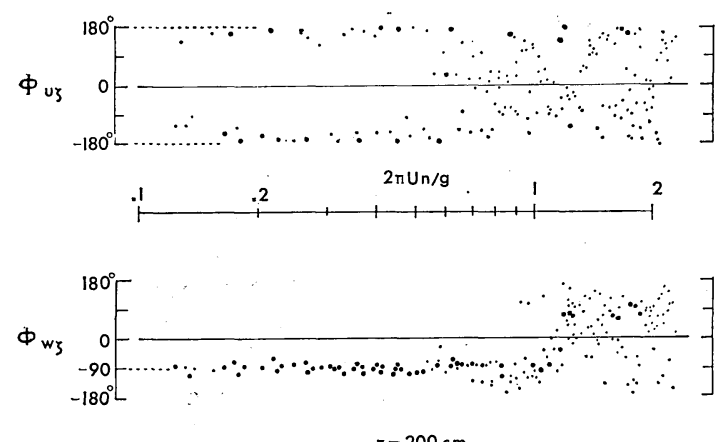

Fig. 11(c) Phase factors between waves and wave coherent perturbations versus dimensionless frequency; $z=200 \mathrm{~cm}$. 

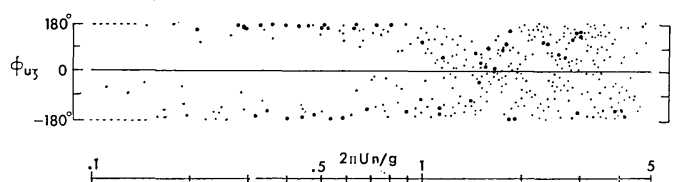

5

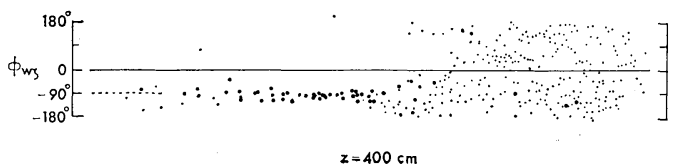

the frequencies, whereas, $2 \pi U n / g>1$, they show

Fig. 11(d) Phase factors between waves and wave coherent perturbations versus dimensionless frequency; $z=400 \mathrm{~cm}$.

respectively, and are undoubtedly independent of random scattering and it might be difficult to find out any systematic features from them. As given in (5.5), a phase factor $\phi$ is identical with a phase lag $\theta$. Confidence limits of $\theta$ depend on a coherence. A large coherence value gives a higher confidence to $\phi$. In Fig. 11, a plot of $\phi$ whose coherence is larger than 0.45 is marked by a large dot, otherwise it is marked by a small dot. Noticing just the plots of large dots in Fig. 11, the above behavior may get more clear.

These behaviors of $\phi_{\zeta \tilde{u}}$ and $\phi_{\zeta \tilde{w}}$ will suggest such a pattern of the wave coherent perturbation as a wave-like orbital motion on an ellipse with a vertical and a horizontal axes in the $x-z$ plane. Such a perturbation will not originate any cospectral density. This agrees with the fact that cospectra excluding the perturbation contributions are almost coincident with original ones, as it was seen in Section 4.3.

\section{Discussions and conclusions}

\subsection{Wave effects in wind spectra of the marine atmospheric surface layer}

In this and the next sections, discussions are made to reconfirm validities of the experimental facts obtained through the foregoing analyses.

On the fact that a normalized spectrum of a wind component in the marine surface layer deviates toward higher density level from that of model universal forms, Busch and Panofsky (1968) first indicated, as mentioned before, the same behavior from comparison of their spectral results over land with those over sea by Weiler and Burling (1967) and by Smith (1967).

Volkov (1969) illustrated a spectrum with an anomalous upward deviation in the frequency range where the major part of energy of a wave spectrum concentrated. In order to remove the anomaly, Volkov tried to cut away the anomalous bulge in the spectrum and replaced with a smooth curve interporated from both sides, but the values $\sigma w^{1} / u_{*}$ obtained from the resultant spectrum was still large.

Pond et al. (1971) reported normalized wind spectra with anomalous deviations around spectral peaks obtained in a stable platform 'FLIP' over the Atlantic Ocean near the Barbados Island. They regarded the deviations as caused by motions of FLIP due to waves, but the deviations seemed to be too large for what induced only by the motions. So the wave coherent perturbations are considered to be added to original turbulence as well as the effects of FLIP motions.

In addition to the above, many wind spectra observed over sea have reported by various investigators as Miyake et al. (1970), Stegen et al. (1973), Naito (1978) and Schmitt et al. (1978). Some of their spectra seem to have ambiguities in the light of the similarity theory, nevertheless the authors did not stated any comments on them.

If a normalized spectrum deviates toward higher side of spectral density levels, an integral of the normalized spectral function over the entire frequency range should increase by total amounts of the deviated parts. The square root of the integral is equal to $\sigma_{u} / u_{*}$ or $\sigma_{w} / u_{*}$, where $\sigma_{u}$ and $\sigma_{w}$ are standard deviations of fluctuations of wind velocity components $u$ and $w$, respectively. According to the similarity theory, $\sigma_{u} / u_{*}$ and $\sigma_{w} / u_{*}$ should depend only on the stability parameter $z / L$ and take a constant value under neutral condition. Most of the above reports provided the observed values of $\sigma_{u} / u_{*}$ and $\sigma_{w} / u_{*}$. In Table 1, given are the values of $\sigma_{u} / u_{*}$ and $\sigma_{w} / u_{*}$ taken over various boundary surfaces by various investigators.

From the table it is found that both $\sigma_{u}^{\prime} / u_{*}$ and $\sigma_{w} / u_{*}$ observed over sea tend to have larger values by several percents at least than those observed over land although there are a few exceptions. This fact implies that wind fluctuations over sea contain more energy than those over land do, and agree with the upward deviation of the spectra over sea from the curves of model spectra which were generalized from a large number of spectra gathered over land.

\subsection{The wave coherent perturbations in winds}

As seen in the foregoing chapters, wind fluctuations observed over sea surely contain wave 
Table 1 Comparison of over-water and over-land values of $\sigma_{u} / u_{*}$ and $\sigma_{w} / u_{*}$ in near-neutral air

\begin{tabular}{lclll}
\hline \multicolumn{1}{c}{ Investigator } & Boundary Surface & $\sigma_{w} / u_{*}$ & $\sigma_{w} / u_{*}$ & \\
\hline Volkov (1969) & sea & $2.3-11.5$ & $1.2-4.5$ & \\
Miyake et al. (1970) & sea & $2.87 \pm 0.52$ & $1.47 \pm 0.22$ & \\
Pond et al. (1971) & sea & - & $1.32 \pm 0.09$ & \\
Davidson (1974) & sea & 2.30 & 1.10 & (at $c / u_{*}=25$ ) \\
& & 2.59 & 1.31 & (at $\left.c / u_{*}=60\right)$ \\
Naito (1978) & sea & 2.49 & $1.23 \pm 0.13$ & \\
McBean (1971) & land & 2.2 & 1.4 & \\
Monin and Yaglom (1971) & land & 2.3 & 1.2 \\
Busch and Larsen (1972) & land & 1.8 & 1.1 \\
Kaimal et al. (1972) & land & 1.8 & 1.1 \\
Merry and Panofsky (1976) & land and sea & - & 1.3 \\
Present results & sea & $2.57 \pm 0.49$ & $1.28 \pm 0.33$ \\
& & $2.29 \pm 0.23^{*}$ & $1.04 \pm 0.16^{*}$ \\
& lake & $2.26 \pm 0.37$ & $1.06 \pm 0.10$ & \\
\hline
\end{tabular}

* Excluding wave coherent parturbations.

coherent perturbations which may interpret the origin of anomalous deviations in their composite spectra. The results reported by Benilov et al. (1974) and Ichikawa and Imasato (1976) give supporting evidences to this fact. Though the methods were different, results of laboratory and field experiments by several investigators also suggest the presence of wave coherent perturbations (Lai and Schemdin 1971, Kato and Sano 1971, Kondo et al. 1972, Davidson 1974).

Contribution of the wave coherent perturbations to individual spectra of $u$ and $w$ should be examined. Fig. 12 shows a typical set of wave coherent perturbation spectra $S_{\tilde{u}}(n)$ and $S_{\tilde{w}}(n)$ (hatched sections) plotted in the linear scale together with their original spectra $S_{u}(n)$ and $S_{w}(n)$. An area of the hatched section illustrates energy contribution of the wave coherent perturbations. In this figure, also plotted are coherences, $R_{u \zeta}(n)$ and $R_{w \zeta}(n)$, and a wave spectrum $S_{\zeta}(n)$ (hatched) of the same record for reference.

The figure will interpret a couple of features relevant to the wave coherent perturbations; one is that their spectral contribution to a total spectrum is unexpectedly large especially in the lower frequency region, and will be far from negligible when one would have a question in the wind fluctuations in the marine atmospheric surface layer; the other is that the local irregularities appearing in the comparatively higher density region of a wind spectrum might come from those appearing in a wave spectrum through the wave coherent perturbations, and can be removed by separation of the perturbation as Benilov et al. (1974) performed.

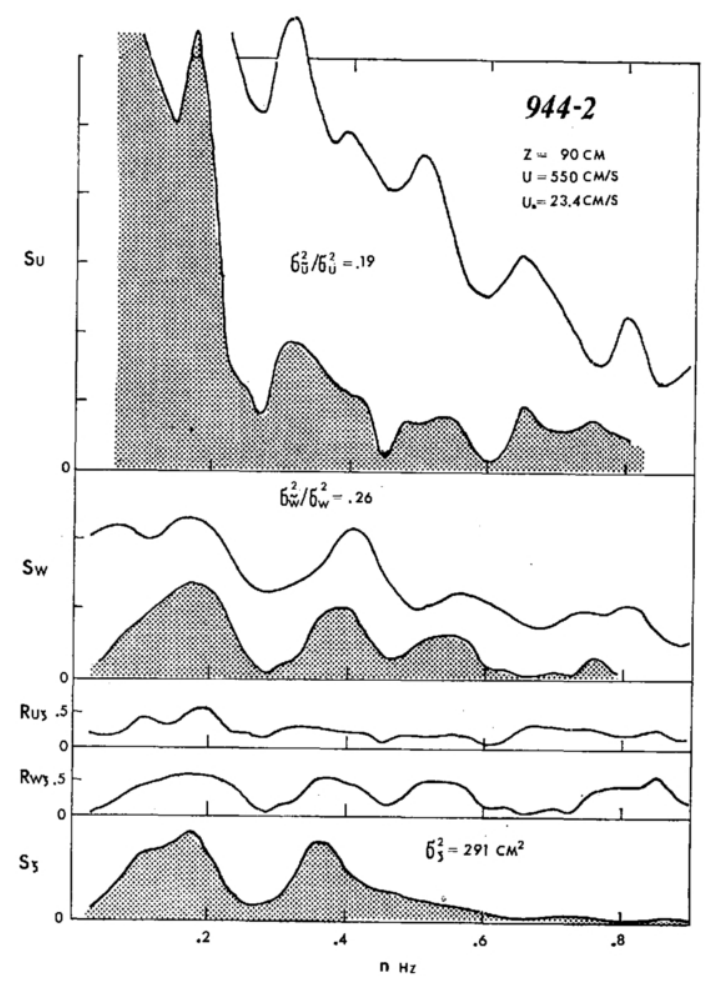

Fig. 12 An example of a linearly plotted spectra set illustrating the contribution of wave coherent perturbations: (top to bottom) $u$ and $\tilde{u}$ (hatched) spectra, $w$ and $\tilde{w}$ (hatched) spectra, $u-\zeta$ coherence, $w-\zeta$ coherence and $\zeta$ spectrum (hatched).

Consequently the features of wind spectra of the marine surface layer mentioned above can be interpret mostly as a result of linear composite 
of a spectrum of the wave coherent perturbations and that of turbulence generally existing in the atmospheric surface layers.

As shown in Figs. 2, 4 and 10, the wave coherent perturbation is supposed to be induced much more effectively by the wave components whose phase speeds exceed the speed of overlying winds. This fact will be supported by another evidence; Volkov (1969) found that an integral of a normalized wind spectrum or $\sigma_{u} / u_{*}$ and $\sigma_{w} / u_{*}$ increased with increasing parameter $c_{1} / u_{*}$, when $c_{1} / u_{*}$ exceeds 25 where $c_{1}$ is a phase speed of the highest peaking component in a wave spectrum, while they should be constant in neutral air over land as seen in the previous section. Here $25 u_{*}$ is known to be comparable with a mean wind velocity $U$ at several meters height above the water surface, then $c_{1}>25 u_{*}$ means

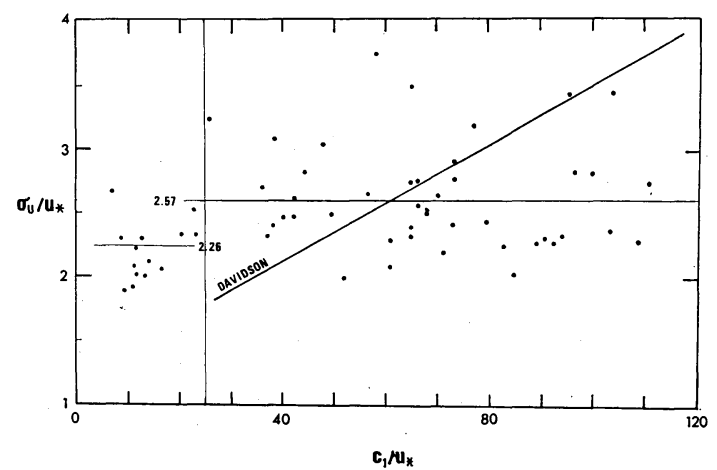

Fig. 13(a) Relation of $\sigma_{u} / u_{*}$ versus $c_{1} / u_{*}$. Numerals indicate the mean values of $\sigma_{u} / u_{*}$ for each region of $c_{1} / u_{*}$ less or larger than $c_{1} / u_{*}=25$. A straight line is the relation proposed by Davidson (1974).

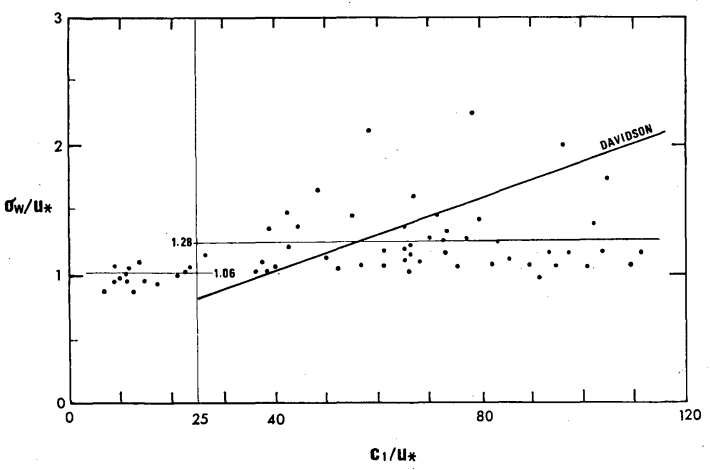

Fig. 13(b) Relation of $\sigma w / u_{*}$ versus $c_{1} / u_{*}$. Numerals indicate the mean values of $\sigma w / u_{*}$ for each region of $c_{1} / u_{*}$ less or larger than $c /{ }_{1} u_{*}=25$. A straight line is the relation proposed by Davidson (1974).
$c_{1}>U$, that is a frequency region where the phase speed of a peaking wave component exceed the overlying wind speed. After all, what Volkhov indicated is no other than that a total energy of wind fluctuations has larger value when the highest peak of a wave spectrum lies in the swell region. Davidson (1974) proposed the relations of $\sigma_{u} / u_{*}$ v.s. $c_{1} / u_{*}$ and $\sigma_{w} / u_{*}$ v.s $c_{1} / u_{*}$, as well as v.s $z / L$, based on statistical analyses of the over-sea data, which have a similar tendency to the result of Volkov.

In Fig. 13, $\sigma_{u} / u_{*}$ and $\sigma_{w} / u_{*}$ obtained from the over-sea and over-lake records under nearneutral condition were plotted against $c_{1} / u_{*}$. The plots of $\sigma_{u} / u_{*}$ and $\sigma_{w} / u_{*}$ which lie in the range $c_{1} / u_{*} \leq 25$ in Figs. 13a and 13b came from the records measured over-lake and concentrated near the values of $\sigma_{u} / u_{*}=2.26$ and $\sigma_{w} / u_{*}=1.06$, respectively. The plots of $\sigma_{u} / u_{*}$ and $\sigma_{w} / u_{*}$ in the range $c_{1} / u_{*}>25$, much scattered to upward and their mean values increased to 2.57 and 1.28 respectively. This fact is surely agree with Volkov's hypothesis. Straight lines in each figure indicate the results of Davidson in the case of $z / L=0$. Comparing with these lines, values of the present results are small. It is supposed that

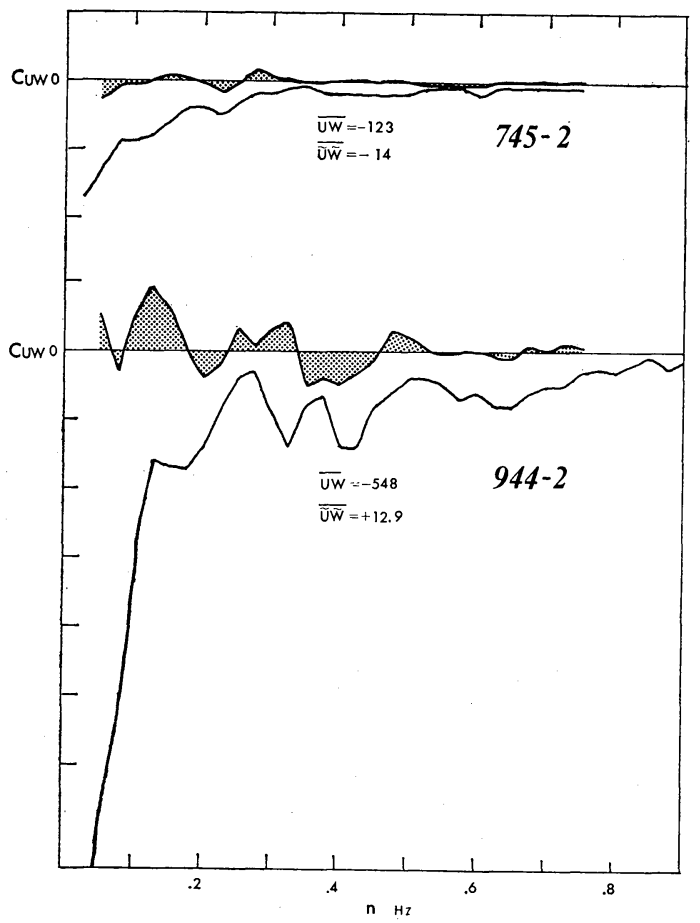

Fig. 14 Examples of linearly plotted cospectra illustrating the contribution of wave coherent perturbations (hatched area). 


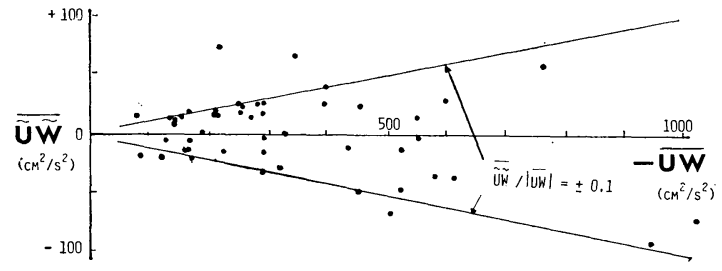

Fig. $15 \overline{\tilde{u} \tilde{w}}$ versus $-\overline{u w}$; lines show $\overline{\tilde{u} \tilde{w}} /|-\bar{u} \bar{w}|$ $= \pm 0.1$

in the present cases, observed swells were at decaying stage as mentioned in Section 3.2 and their energy was much less than those at developing stage. Because of this reason, the $\sigma / u *$ values may be small. It should be noted that the bottom of the area where the $\sigma / u_{*}$ scattered is clearly bounded by a line $\sigma / u_{*}=$ constant.

One of the most important results in this study is that the wave coherent perturbations may give little contribution to a cospectrum, or hardly transfer wind momentum toward the boundary surface. Typical examples are plotted linearly in Fig. 14 so that an area surrounded by the two axes of coordinates and a cospectral curve is proportional to a covariance value. Contribution of the perturbation illustrated by a hatched area is small, and is regarded within a range of errors in each case. This fact is also presented by values of covariances $-\bar{u} \bar{w}$ and $\overline{\tilde{u}} \tilde{w}$ in the same figure. In order to make sure of the fact for all the 48 records obtained over sea in near-neutral conditions, values of $\overline{\tilde{u}} \tilde{w}$ are plotted against those of $-\overline{u w}$ in Fig. 15. Ratio $\overline{\tilde{u} \tilde{w}} /|\overline{u w}|$ lies within a range from -0.1 to +0.1 in almost all the cases. The mean value of the ratios is -0.009 and the standard deviation of them is 0.057 .

From the obtained frequency response functions in Figs. 10 and 11, a pattern of an ellipse may be inferable for the orbital motion of the perturbation. The observed perturbations may be similar to those which appear in a still air over an undulating water surface as Harris (1966) reported.

Because of a limited range of height an entire behavior of vertical profile of the gain factor has not been grasped. But it is reasonable to infer that the wave coherent perturbations will relatively stand out in the lowest layer. The perturbations are expected to be periodic like wave motions and to have comparatively large amplitudes. A cup anemometer may not fully respond to such a periodic wind fluctuation. One trying to measure a mean wind speed in the layer by a cup anemometer should note an overestimate due to overrunning of the roter. Kinks in a wind profile reported by Takeda (1963) may possively be associated with an overestimate of this type.

The results of frequency response function are much interesting in relation to the theoretical approach for the critical layer instability, as Kondo et al. (1972) suggested. Further study will be required to describe the physical processes relevant to the wave coherent perturbations.

The present study dealed only with the case when all the components of waves travel almost in parallel to the wind. The case is considered to be the most common and basically important. But it turned out in this study that swells influence much the characteristics of the overlying wind fluctuations. Swells propagate toward any directions unrelated to winds. Kondo et al. (1972) showed a case in which swells propagate to up-wind direction might involve different behaviors of the wind fluctuations. Further experimental investigation on various combinations of wind and wave conditions will also be needed to interpret effects of the wave coherent perturbation in general cases.

\subsection{Conclusions}

In conclusion, wave effects on spectral characteristics of winds in the marine atmospheric surface layer may be recognized from the facts as follows.

1) The wind fluctuations in a marine atmospheric surface layer may contain a fairly good amount of wave coherent perturbations in addition to turbulences, characteristics of which are supposed to be identical to those over land.

2) Because of wave coherent perturbations, a normalized spectrum of wind velocity component in the layer may deviate much toward higher side from the corresponding model spectrum established over land, in the frequency region around the peak of the model spectrum and lower than it. A spectrum excluding the contribution of the perturbations is very similar to the corresponding model.

3) The perturbation may be interpreted as a linear response of underlying wave motion. It is induced much more effectively in the frequency range where wave components propagate faster than the mean wind speed. Consequently, it stands out when swells are dominant and almost dies out over water surfaces without such swells.

4) Dependence of the perturbation on height was not clear within the height range from 
$0.5 \mathrm{~m}$ to $4 \mathrm{~m}$.

5) The perturbation may contribute little to a cospectrum between $u$ and $w$, and consequently little to the momentum flux from wind to water. A pattern of orbital motion of the perturbation like an ellipse with a horizontal axis which is a little longer than a vertical one may be inferred.

The above mentioned wave effects on over-sea wind spectra were first described on the basis of the similarity theory in this study. The effects are considered to be important for problems in the marine atmospheric surface layer in relation to the air-sea interaction. Further experimental investigation under various conditions of winds and waves will be needed. Theoretical approach is also required to understand the physical processes of the wave coherent perturbations.

\section{Acknowledgements}

The author wishes to thank Professor Yoshimitsu Ogura of University of Illinois for his guidance to this study. He also wishes to thank the late Professor Kozo Yoshida of University of Tokyo for his encouragement during the course of this study.

This study was conducted as a part of a programme of Ocean Research Institute, University of Tokyo since 1965. Many people of the Institute provided assistance in various stages of the programme. The author is especially grateful to Dr. Keisuke Taira, Mr. Koji Ishikawa and Mr. Nobuhiko Misawa for their help in field works and data analyses. The Hiratsuka Marine Observation Tower is a facility of Institute of Coastal Oceanology, National Research Center for Disaster Prevention, Science and Technology Agency. The author is grateful for permission to use the facility and assistance to the group of the Institute led by Dr. Noriyuki Iwata. The author carried out most analytical work of this study at School of Meteorology, University of Oklahoma. He would express his gratitude to Professor Yoshikazu Sasaki of the University for providing the opportunity.

The author is much indebted to Professor Tomio Asai of Ocean Research Institute, University of Tokyo for invaluable comments on improving the paper. This work was partly supported by Scientific Research Fund of Ministry of Education for GARP/AMTEX.

\section{Appendix 1}

Dependence of the drag coefficients on wind speed
One of the most interesting problems relevant to the marine atmospheric surface layer is dependence of the drag coefficients of sea surface on wind speeds. The drag coefficient $C d$ is considered as a normalized momentum flux across the sea surface and defined by

$$
C d=u_{*}^{2} / U^{2}(z)
$$

or

$$
=\tau_{0} / \rho U^{2}(z)
$$

where $u_{*}$ is a friction velocity, $U(z)$ is a mean wind speed varying with heights, $\tau_{0}$ is a momentum flux at the surface or a surface stress determined directly by $-\rho \overline{w u}$ in a surface layer and $\rho$ is air density. In usual, the drag coefficient for a wind speed at $10 \mathrm{~m}$ height, $C d_{10}$ is used for discussion as a representative parameter. It is given by

$$
C d_{10}=u_{*}^{2} / U_{10}^{2}
$$

where $U_{10}$ is a mean wind speed at $10 \mathrm{~m}$ height.

In this study, $u_{*}$ was obtained from the measured covariance $\overline{u w}$ by

$$
u_{*}=\sqrt{|\overline{u w}|}
$$

and $U_{10}$ was computed by the well-known following relation

$$
U_{10}=U+\frac{u_{*}}{k}\left[\ln \frac{10}{z}-\beta \frac{z}{L}\left(\frac{10}{z}-1\right)\right]
$$

where $U$ is an observed mean wind speed at an anemometer height $z, k$ is von Karman constant, $L$ is the Monin-Obukhov length given by (2.1) and a constant $\beta$ may be reasonably taken as

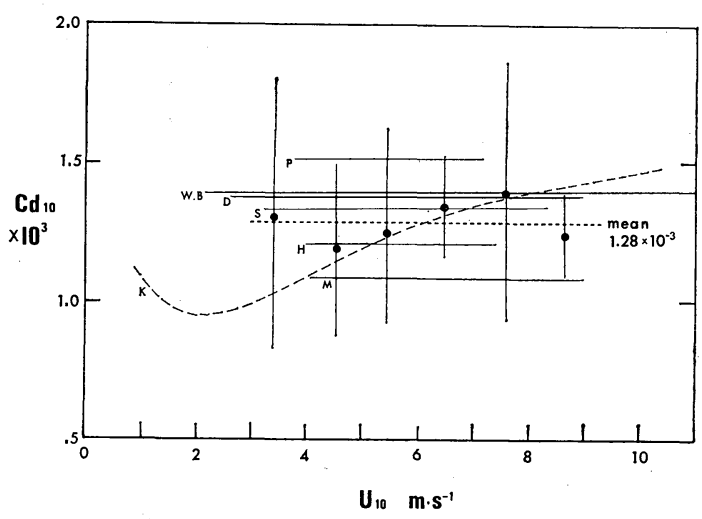

Fig. A1 Drag coefficients $C_{d 10}$ in near neutral conditions versus wind $U_{10}$ : present results (•) comparing with reported $C_{d 10}-U_{10}$ relations by others; W. B. Weiler and Burling (1967), H. Hasse (1970), D. Dunckel et al. (1974), K. Kondo (1975) (refer the bibliography of this paper). 
6 for near neutral cases (Lumley and Panofsky, Fig. A-1 by solid circles. Each plot is an average 1964). over every one $\mathrm{m} / \mathrm{s}$ range of $U_{10}$ between $3 \mathrm{~m} / \mathrm{s}$

As it is found in this study that the wave and $9 \mathrm{~m} / \mathrm{s}$. The vertical segment on a circle coherent perturbations of winds in a marine indicates the standard deviation. The result atmospheric surface layer may contribute little shows a tendency that $C_{d 10}$ is almost independent to a covariance $\overline{u w}$, all the near-neutral records of $U_{10}$ within this range of wind speeds. The gathered both over sea and over lake (sixty-five mean value of the obtained $C_{d 10}$ is $(1.28 \pm 0.32) \times$ in total) were equally treated when $C_{d 10}$ was $10^{-3}$. It seems to be much the same as the computed.

results recently reported by several investigators

Obtained relation $C_{d 10}$ vs $U_{10}$ are plotted in shown in the same figure.

Appendix 2 Inventory of Records Selected for the Investigation

\begin{tabular}{|c|c|c|c|c|c|c|c|c|c|}
\hline $\begin{array}{l}\text { Record O } \\
\text { No. }\end{array}$ & $\begin{array}{l}\text { Observation }^{1} \\
\text { Site }\end{array}$ & $\begin{array}{l}\text { Time } 2) / \text { Date } \\
\text { (GMT-9hr) }\end{array}$ & $\begin{array}{c}z_{a}^{3)} \\
(\mathrm{cm})\end{array}$ & $\begin{array}{c}U_{a} \\
\left(\mathrm{~cm} \cdot \mathrm{s}^{-1}\right)\end{array}$ & $\begin{array}{c}u_{*} \\
\left(\mathrm{~cm} \cdot \mathrm{s}^{-1}\right)\end{array}$ & $z / L$ & $\begin{array}{c}\overline{u^{2}} \\
\left(\mathrm{~cm}^{2} \cdot \mathrm{s}^{-2}\right)\end{array}$ & $\begin{array}{c}\overline{w^{2}} \\
\left(\mathrm{~cm}^{2} \cdot \mathrm{s}^{-2}\right)\end{array}$ & $\begin{array}{c}c_{1}^{4)} \\
\left(\mathrm{cm} \cdot \mathrm{s}^{-1}\right)\end{array}$ \\
\hline $741-1$ & $\mathbf{H}$ & $1650 / 25 / 4 / ' 67$ & 90 & 455 & 19.9 & 0 & 1969 & 354 & 1210 \\
\hline-2 & $\mathrm{H}$ & 1657 & 90 & 426 & 22.8 & 0 & 2755 & 451 & 1330 \\
\hline $743-1$ & $\mathbf{H}$ & $1301 / 26 / 4 / ' 67$ & 155 & 283 & 12.8 & -0.018 & 892 & 177 & 1210 \\
\hline-2 & $\mathrm{H}$ & 1308 & 155 & 271 & 11.7 & -0.021 & 766 & 181 & 1210 \\
\hline $744-1$ & $\mathrm{H}$ & 1347 & 145 & 279 & 13.0 & -0.020 & 877 & 217 & 1210 \\
\hline-2 & $\mathrm{H}$ & 1354 & 145 & 257 & 15.0 & -0.015 & 740 & 229 & 1210 \\
\hline $745-1$ & $\mathbf{H}$ & 1514 & 50 & 261 & 14.5 & -0.001 & 1186 & 292 & 1210 \\
\hline-2 & $\mathrm{H}$ & 1521 & 50 & 248 & 11.1 & -0.002 & 912 & 163 & 1210 \\
\hline $941-1$ & $\mathrm{H}$ & $1407 / 23 / 4 / ' 69$ & 400 & 453 & 16.5 & -0.069 & 2309 & 349 & 1210 \\
\hline-2 & $\mathbf{H}$ & 1414 & 400 & 446 & 14.5 & -0.091 & 1057 & 320 & 1210 \\
\hline$-3 * * *$ & $\mathrm{H}$ & 1421 & 400 & 405 & 12.4 & -0.122 & 754 & 323 & 890 \\
\hline $942-1$ & $\mathrm{H}$ & 1440 & 400 & 454 & 15.5 & -0.065 & 1383 & 464 & 1210 \\
\hline-2 & $\mathbf{H}$ & 1447 & 400 & 491 & 16.7 & -0.054 & 1619 & 419 & 1210 \\
\hline-3 & $\mathrm{H}$ & 1454 & 400 & 521 & 21.3 & -0.033 & 3127 & 664 & 890 \\
\hline $943-1$ & $\mathrm{H}$ & 1522 & 400 & 558 & 22.3 & -0.034 & 3062 & 543 & 890 \\
\hline-2 & $\mathrm{H}$ & 1529 & 400 & 595 & 24.1 & -0.029 & 3265 & 685 & 1330 \\
\hline $944-1$ & $\mathrm{H}$ & 1641 & 90 & 527 & 23.4 & -0.006 & 3630 & 657 & 1330 \\
\hline-2 & $\mathrm{H}$ & 1648 & 90 & 550 & 24.5 & -0.006 & 4412 & 732 & 890 \\
\hline-3 & $\mathrm{H}$ & 1655 & 90 & 520 & 24.7 & -0.006 & 3811 & 816 & 1210 \\
\hline $945-1$ & $\mathrm{H}$ & $0900 / 24 / 4 / ' 69$ & 260 & 402 & 12.0 & -0.025 & 1141 & 264 & 1210 \\
\hline-2 & $\mathrm{H}$ & 0907 & 260 & 461 & 13.7 & -0.020 & 976 & 204 & 1210 \\
\hline-3 & $\mathrm{H}$ & 0914 & 260 & 417 & 12.1 & -0.025 & 735 & 162 & 1210 \\
\hline $948-1$ & $\mathbf{H}$ & 1035 & 260 & 727 & 28.6 & 0 & 5012 & 1773 & 1210 \\
\hline $949-1$ & $\mathrm{H}$ & $1259 / 28 / 4 / ' 69$ & 60 & 373 & 17.7 & 0 & 1950 & 334 & 1210 \\
\hline $950-1$ & $\mathrm{H}$ & 1312 & 60 & 386 & 17.1 & +0.004 & 2538 & 537 & 1110 \\
\hline-2 & $\mathrm{H}$ & 1319 & 60 & 357 & 17.6 & +0.008 & 1565 & 436 & 1110 \\
\hline-3 & $\mathbf{H}$ & 1326 & 60 & 345 & 18.1 & +0.003 & 1419 & 365 & 1110 \\
\hline-4 & $\mathrm{H}$ & 1333 & 60 & 379 & 21.2 & +0.003 & 1749 & 428 & 1110 \\
\hline $951-1$ & $\mathrm{H}$ & 1507 & 200 & 460 & 17.1 & -0.006 & 1637 & 360 & 1210 \\
\hline-2 & $\mathrm{H}$ & 1514 & 200 & 461 & 16.9 & -0.007 & 2168 & 376 & 1110 \\
\hline-51 & $\mathrm{H}$ & 1508 & 200 & 463 & 17.0 & -0.007 & 1609 & 339 & 1110 \\
\hline-52 & $\mathrm{H}$ & 1515 & 200 & 457 & 17.1 & -0.006 & 2109 & 470 & 1110 \\
\hline-53 & $\mathrm{H}$ & 1522 & 200 & 421 & 18.2 & -0.006 & 1738 & 407 & 1110 \\
\hline-54 & $\mathrm{H}$ & 1529 & 200 & 429 & 14.6 & -0.009 & 1328 & 343 & 1000 \\
\hline $952-1$ & $\mathrm{H}$ & $1452 / 7 / 5 / ' 69$ & 95 & 384 & 16.8 & -0.028 & 1818 & 376 & 1110 \\
\hline-2 & $\mathbf{H}$ & 1459 & 95 & 396 & 14.4 & -0.039 & 2113 & 336 & 1110 \\
\hline-3 & $\mathbf{H}$ & 1506 & 95 & 416 & 15.8 & -0.032 & 1716 & 383 & 1110 \\
\hline $953-1$ & $\mathbf{H}$ & $1442 / 8 / 5 / ' 69$ & 120 & 668 & 29.0 & -0.004 & 4826 & 918 & 1110 \\
\hline $954-1$ & $\mathrm{H}$ & 1458 & 120 & 376 & 15.2 & -0.010 & 1770 & 402 & 1110 \\
\hline $102-1 *$ & $\mathrm{~K}$ & 0931/4/12/'71 & 70 & 257 & 12.2 & +0.009 & 833 & 167 & 279 \\
\hline$-2^{*}$ & K & 0983 & 70 & 255 & 12.2 & +0.009 & 954 & 161 & 270 \\
\hline$-3 *$ & K & 0945 & 70 & 234 & 12.7 & +0.008 & 887 & 160 & 265 \\
\hline $103-2 \mathrm{~L} *$ & $\mathrm{~K}$ & 1049 & 70 & 515 & 19.2 & +0.009 & 1504 & 273 & 238 \\
\hline
\end{tabular}




\begin{tabular}{|c|c|c|c|c|c|c|c|c|c|}
\hline $\begin{array}{l}\text { Record Obs } \\
\text { No. }\end{array}$ & $\begin{array}{l}\text { bservation } 1 \\
\text { Site }\end{array}$ & $\begin{array}{l}\text { Time } 2) / D a t e \\
\text { (GMT-9hr) }\end{array}$ & $\begin{array}{c}z_{a}^{3)} \\
(\mathrm{cm})\end{array}$ & $\begin{array}{c}U_{a} \\
\left(\mathrm{~cm}^{\prime} \mathrm{s}^{-1}\right)\end{array}$ & $\begin{array}{c}u_{*} \\
\left(\mathrm{~cm} \cdot \mathrm{s}^{-1}\right)\end{array}$ & $z / L$ & $\begin{array}{c}\overline{u^{2}} \\
\left(\mathrm{~cm}^{2 \cdot \mathrm{s}^{-2}}\right)\end{array}$ & $\begin{array}{c}\overline{w^{2}} \\
\left(\mathrm{~cm}^{2 \cdot} \cdot \mathrm{s}^{-2}\right)\end{array}$ & 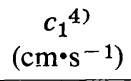 \\
\hline$-2 \mathrm{H}^{*}$ & $\mathrm{~K}$ & 1049 & 220 & .555 & 18.1 & +0.032 & 1322 & 414 & 250 \\
\hline$-6 \mathrm{~L} *$ & $\mathrm{~K}$ & 1117 & 70 & 436 & 17.6 & +0.011 & 1104 & 308 & 250 \\
\hline$-6 H^{*}$ & $\mathrm{~K}$ & 1117 & 220 & 451 & 17.6 & +0.034 & 1440 & 384 & 250 \\
\hline $104-1 *$ & $\mathrm{~K}$ & 1234 & 60 & 299 & 13.9 & +0.015 & 824 & 163 & 238 \\
\hline $105-1 *$ & $\mathrm{~K}$ & $1500 / 4 / 12 / ’ 71$ & 60 & 258 & 18.1 & +0.011 & 1490 & 361 & 221 \\
\hline $106-2 *$ & $\mathrm{~K}$ & 1933 & 320 & 637 & 28.5 & -0.001 & 3008 & 880 & 274 \\
\hline $107-1 *$ & K & 2017 & 320 & 714 & 24.3 & -0.008 & 2610 & 711 & 274 \\
\hline $108-1 *$ & K & 2058 & 120 & 623 & 28.5 & -0.004 & 3176 & 996 & 270 \\
\hline$-2 *$ & K & 2105 & 120 & 558 & 25.1 & -0.006 & 2722 & 681 & 270 \\
\hline$-3 *$ & K & 2112 & 120 & 524 & 25.3 & -0.005 & 2588 & 892 & 270 \\
\hline $109-1 *$ & $\mathrm{~K}$ & 2158 & 120 & 318 & 11.8 & -0.024 & 1462 & 189 & 312 \\
\hline $224-3 *$ & $\mathrm{~B}$ & $0629 / 18 / 12 \gamma^{\prime} 71$ & 250 & 508 & 25.7 & -0.055 & 5711 & 599 & 218 \\
\hline$-4 *$ & B & 0636 & 250 & 675 & 34.7 & -0.030 & 8722 & 833 & 213 \\
\hline$-9 *$ & B & 0711 & 250 & 377 & 15.8 & -0.090 & 1340 & 304 & 209 \\
\hline $544-1 \mathrm{~L} * *$ & $\mathrm{H}$ & $1355 / 9 / 8 / ’ 75$ & 260 & 214 & 7.9 & +0.215 & 665 & 129 & 1110 \\
\hline$-1 \mathrm{H} * *$ & * $\mathrm{H}$ & 1355 & 510 & 274 & 7.4 & +0.482 & 859 & 451 & 1110 \\
\hline$-2 \mathrm{~L} * *$ & $\mathrm{H}$ & 1402 & 260 & 224 & 8.3 & +0.195 & 398 & 134 & 1110 \\
\hline$-2 \mathrm{H}^{* * *}$ & $\mathrm{H}$ & 1402 & 510 & 291 & 8.9 & +0.333 & 378 & 176 & 1110 \\
\hline$-3 L * *$ & $\mathrm{H}$ & 1409 & 260 & 197 & 7.0 & +0.274 & 297 & 121 & 1110 \\
\hline$-3 \mathrm{H} * *$ & $\mathrm{H}$ & 1409 & 510 & 258 & 7.1 & +0.523 & 245 & 271 & 1110 \\
\hline$-4 \mathrm{H} * *$ & $\mathrm{H}$ & 1416 & 510 & 237 & 7.6 & +0.456 & 533 & 260 & 1110 \\
\hline$-5 \mathrm{~L} * *$ & $\mathrm{H}$ & 1423 & 260 & 176 & 4.5 & +0.664 & 294 & 96 & 1110 \\
\hline$-5 H^{* *}$ & $\mathrm{H}$ & 1423 & 510 & 223 & 4.8 & +1.144 & 287 & 129 & 1110 \\
\hline$-6 L * *$ & $\mathrm{H}$ & 1430 & 260 & 191 & 8.6 & +0.182 & 420 & 114 & 1110 \\
\hline$-6 H^{* * *}$ & $\mathbf{H}$ & 1430 & 510 & 240 & 9.1 & +0.318 & 606 & 400 & 1110 \\
\hline $545-2 \mathrm{~L}$ & $\mathbf{H}$ & 1616 & 40 & 223 & 12.5 & +0.013 & 1235 & 195 & 1210 \\
\hline$-2 H^{* *}$ & $\mathrm{H}$ & 1616 & 430 & 346 & 12.5 & +0.142 & 1617 & 796 & 1210 \\
\hline$-3 \mathrm{~L}$ & $\mathbf{H}$ & 1623 & 40 & 183 & 9.3 & +0.024 & 548 & 242 & 1210 \\
\hline$-3 H^{* * *}$ & $\mathrm{H}$ & 1623 & 430 & 242 & 8.8 & +0.365 & 520 & 372 & 1210 \\
\hline$-4 \mathrm{~L}$ & $\mathrm{H}$ & 1630 & 40 & 192 & 11.6 & +0.015 & 1590 & 389 & 1210 \\
\hline$-5 \mathrm{~L}$ & $\mathrm{H}$ & 1637 & 40 & 182 & 8.6 & +0.028 & 475 & 392 & 1210 \\
\hline $546-2$ & $\mathrm{H}$ & 1732 & 60 & 128 & 14.2 & +0.021 & 804 & 114 & 1210 \\
\hline-3 & $\mathrm{H}$ & 1739 & 60 & 177 & 16.2 & +0.016 & 527 & 184 & 1210 \\
\hline $556-1$ & $\mathbf{H}$ & $1830 / 10 / 8 / ’ 75$ & 190 & 849 & 30.7 & +0.015 & 9522 & 2013 & 1210 \\
\hline-2 & $\mathrm{H}$ & 1837 & 190 & 711 & 32.0 & +0.006 & 9781 & 1852 & 1210 \\
\hline-3 & $\mathrm{H}$ & 1844 & 190 & 668 & 27.6 & +0.008 & 6065 & 1439 & 1210 \\
\hline-4 & $\mathbf{H}$ & 1851 & 190 & 623 & 22.9 & +0.012 & 4861 & 1449 & 1110 \\
\hline
\end{tabular}

Remarks: *, over-lake cases (18), **, over-sea stable cases (13), ***, over-sea unstable cases (1). otherwise, over-sea near neutral cases (47).

1) H; Hiratsuka Marine Observation Tower, K; Lake Kasumigaura, B; Lake Biwa.

2) time when a record started. 3) above mean sea level. 4) phase speed of wave component with the highest peak in wave spectrum.

\section{References}

Bendat, J. S. and A. G. Piersol, 1971: 'Random Data: Procedure of Analysis and Measurement' New York, John Wiley \& Sons, $390 \mathrm{pp}$.

Benilov, A. Yu., O. A. Kouznetsov and G. N. Panin, 1974: On the analysis of wind wave-induced disturbances in the atmospheric turbulent surface layer. Boundary-Layer Meteor., 6, 269-285.

Busch, N. E., 1973: Turbulence structure in the planetary boundary layer, Part 1: The surface boundary layer. Boundary-Layer Meteor., 4, 213-
240.

Busch, N. E. and H. A. Panofsky, 1968: Rceent spectra of atmospheric turbulence. Quart. J. Roy. Meteor. Soc., 94, 132-148.

Busch, N. E. and S. E. Larsen, 1972: Spectra of turbulence in the atmospheric surface layer. Riso Rep., No. 256, 187-207.

Davidson, K. L., 1974: Observational results on the influence of stability and wind-wave coupling on momentum transfer and turbulent fluctuations over ocean waves. Boundary-Layer Meteor. 6, 305-331. 
Dunckel, M., L. Hasse, L. Krügermeyer, D. Schriever and J. Wucknitz, 1974: Turbulent fluxes of momentum, heat and water vapor in the atmospheric surface layer at sea during ATEX. Boundary-Layer Meteor., 6, 81-106.

Harris, D. Lee, 1966: The wave-driven wind. $J$. Atmos. Sci., 23, 688-693.

Hasse, L., 1970: On the determination of the vertical transports of momentum and heat in the atmospheric boundary layer at sea. Tech. Rep., 88, Dept. of Oceanography, Oregon State Univ., $55 \mathrm{pp}$.

Ichikawa, H. and N. Imasato, 1976: The wind field over wind-waves. J. Oceanogr. Soc. Japan, 32, 271-283.

Inada, W. and I. Watabe, 1969: Capacitance-type ocean wave meter (in Japanese). Rep. Nat. Res. Ctr. for Disaster Prevention, Japan, 2, 57-68.

Kaimal, J. C., J. C. Wyngaard, Y. Izumi and O. R. Coté, 1972: Spectral characteristics of surfacelayer turbulence. Quart. J. Roy. Meteor. Soc., 98, 563-589.

Kato, H. and K. Sano, 1971: An experimental study of the turbulent structure of wind over water waves. Rep. Port and Harbour Res. Inst., Japan, 10, 2 .

Kondo, J., 1975: Air-sea bulk transfer coefficients in diabatic conditions. Boundary-Layer Meteor., 9, 91-112.

Kondo, J., Y. Fujinawa and G. Naito, 1972: Waveinduced wind fluctuation over the sea. J. Fluid Mech., 51, 751-771.

Lai, R. J. and O. H. Shemdin, 1971: Laboratory investigation of air turbulence above simple water waves. J. Geophys. Res., 76, 7334-7350.

Lumley, J. L. and H. A. Panofsky, 1964: The structure of atmospheric turbulence. New York, Interscience Publishers, $239 \mathrm{pp}$.

McBean, G. A., 1971: The variations of the statistics of wind, temperature and humidity fluctuations with stability. Boundary-Layer Meteor., 1, 438-457.

Merry, M. and H. A. Panofsky, 1976: Statistics of vertical motion over land and water. Quart. J. Roy. Meteor, Soc., 102, 255-260.

Miles, J. W., 1957: On the generation of surface waves by shear flows, Part 1. J. Fluid Mech., 3, 185-204.

_- 1967: On the generation of surface waves by shear flows, Part 5. J. Fluid Mech., 30, 163175.

Mitsuta, Y., 1968: Application of sonic anemometer-thermometer to the studies of vertical eddy transport processes in the atmospheric boundary layer. Special Contributions, Geophys. Inst. Kyoto
Univ., 8, 45-60.

Miyake, M., M. Donelan, G. McBean, C. Paulson, F. Badgley and E. Leavitt, 1970: Comparison of turbulent fluxes over water determined by profile and eddy correlation techniques. Quart. J. Roy. Meteor. Soc., 96, 132-137.

Miyake, M., R. W. Stewart and R. W. Burling, 1970: Spectra and cospectra of turbulence over water. Quart. J. Roy. Meteor. Soc., 96, 138-143.

Monin, A. S. and A. M. Obukhov, 1954: Basic regularity in turbulent mixing in the surface layer of the atmosphere. Trudy Geophys. Inst. ANSSSR, 24, 163 pp.

Monin, A.S. and A. M. Yaglom, 1971: Statistical fluid mechanics; mechanics of turbulence. The MIT Press, Cambridge, $769 \mathrm{pp}$.

Munk, W. H., F. E. Snodgrass and M. J. Tucker, 1959: Spectra of low-frequency ocean waves. Bull. Scripps Inst. Oceanogr., 7, 283-362.

Naito, G., 1978: Direct measurements of momentum and sensible heat fluxes at the tower in the open sea. J. Meteor. Soc. Japan, 56, 25-34.

Phillips, O. M., 1977: The dynamics of the upper ocean (2nd ed.). New York, Cambridge Univ. Press, $336 \mathrm{pp}$.

Pond, S., G. T. Phelps, J. E. Paquin, G. McBean and R. W. Stewart, 1971: Measurements of turbulent fluxes of momentum, moisture and sensible heat over the ocean. J. Atmos. Sci., 28, 901-917.

Schmitt, K. F., C. A. Friehe and C. H. Gibson, 1979: Structure cf marine surface layer turbulence. J. Atmos. Sci., 36, 602-618.

Smith, S. D., 1967: Thrust-anemometer measurements of wind-velocity spectra and Reynolds stress over a coastal inlet. J. Marine Res., 25, 239-262.

, 1970: Thrust-anemometer measurement of wind turbulence, Reynolds stress and drag coefficient over the sea. J. Geophys. Res., 75, 67586770.

Stegen, G. R., C. H. Gibson and C. A. Friehe, 1973: Measurements of momentum and sensible heat fluxes over the open ocean. J. Phys. Oceanogr., 3, 86-92.

Takeda, A., 1963: Wind profiles over sea waves. J. Oceanogr. Soc. Japan, 19, 136-142.

Volkov, Yu. A., 1969: The spectra of velocity and temperature fluctuations in airflow above the agitated sea surface. Bull (Izv.) Atmos. and Oceans Phys., 5, 1251-1265 (Engl. transl. 723730).

Weiler, H. S. and R. W. Burling, 1967: Direct measurements of stress and spectra of turbulence in the boundary layer over the sea. J. Atmos. Sci., 24, 653-664. 


\title{
海面に接する大気境界層内の風速変動のスペクトル特性に 及ぼす水面波動の影響
}

\author{
竹田厚 \\ 国立防災科学技術センター平塚支所
}

水面の波動から受ける影響に特に注目して，海面に接した大気境界層中の 風速 变 動のスペクトル特性を調ベ た。

海上の観測塔などで得られた, 波浪と風速变動の同時測定のデータの中から, 風と波浪の進行方向が大体一致 している場合の例を撰びスペクトル解析等を扣こない，波浪上の，風速の水平平均風向成分 $u$ と鉛直成分 $w$ につ いての 2 次元的な風速変動の場についていろいろと検討した。その結果つぎのような事実が分った。

1. 海面上で測定されたスペクトルは $u$ 成分， $w$ 成分とも Monin-Obukhov の相似理論に基くモデル(ここで は多く実験結果をまとめて導いた Kaimal ら (1972)のものと Busch (1973) のものを引用した) にくらべて主と して低周波側で, 顕著な上向きの偏倚を生じる。モデルスペクトルからの, このような偏倚は Busch-Panofsky (1968) そよっても示唆されている。

2. これらの風速変動中には, 通常の大気境界層の乱流とは別に, 水面の波動とコヒーレントな擾乱が，かな りの割合で含まれていることが，今回の関連度関数の解析から明らかになった。この擾乱のスペクトルへの寄与 を推定し，それを測定されたスペクトルから引き去ると，偏倚はほとんどなくなって，モデルスペクトルに大体 一致したスペクトルが得られる。

3. $u$ とwのコスペクトルに対するこの擾乱による寄与は小さいと推定され, 事実, 測定されたコスペクトル は Kaimal らのモデルコスペクトルの形にほとんど一致している。コスペクトルの積分形である共分散 $\overline{u w}$ は運 動量の鈶直輸送を形成するが,これに対するこの擾乱の寄与は概ね10\%以下で測定誤差の程度であると思われる。 これは本研究の結果の中でとくに注目すべきことがらであろう。

4. 水面の波動を入力としてこの擾乱を出力とする線形応答系を想定し応答関数を求めてみた結果, この擾乱 は，風速よりも速い位相速度をもつ波浪の成分波すなわちらねりによって効果的に引き起こされることが示され た。摄乱の $u$ 成分は $w$ 成分より若干大きめでありどちらも海面からの高度による減衰は今回の高度 $5 \mathrm{~m}$ までの 測定範囲では顕著でない。また，らねりの周波数域でのこの擾乱の両成分の間には，かなり明確な $90^{\circ}$ の位相差 がみられるところから，この擾乱は，今回の観測条件で，平均風向の鉛直面内では，長軸が水平な楕円の軌道運 動をしているものと推測される。

上に述べた実験結果から，海上の風速変動スペクトルに現われる偏倚は水面の波動とコヒーレントな擾乱によ って生じることが認められた。相似則を基礎にしてこのような水面波動の影響を記述したのは本研究がはじめて であろら。

以上のような興味ある事実を, さらに明確に記述するために, 波と風のいろいろな条件のもとでのデータの解 析と, 流体力学の理論とにもとづいた研究が必要であろう。 